\title{
OTIMIZAÇÃO DO USO DE UM ASPERSOR TIPO CANHÃO EM FUNÇÃO DAS CARACTERÍSTICAS OPERACIONAIS E VELOCIDADE MÉDIA DO VENTO
}

\author{
CLÁUDIO TOMAZELA
}

Engenheiro Agrônomo

Orientador: Prof. Dr. TARLEI ARRIEL BOTREL

Tese apresentada à Escola Superior de Agricultura "Luiz de Queiroz" da Universidade de São Paulo, para obtenção do Título de Doutor em Agronomia, Área de Concentraçåo: Imigação e Drenagem

PIRACICABA

Estado de São Paulo-Brasil

Abril de 1996 
Dados Internacionais de Catalogaçāo na Publicaçāo (CIP)

DIVISÃO DE BIBLIOTECA E DOCUMENTAÇÃ̃O - Campus “Luiz de Queiroz"/uSP

Tomazela, Cláudio

Otimização do uso de um aspersor tipo canhão em função das caracteristicas operacionias e velocidade média do vento / Cláudio Tomazela. - - Piracicaba, 1996.

59p. : il.

Tese (doutorado) - Escola Superior de Agricultura Luiz de Queiroz, 1996.

Bibliografia.

1. Água de irrigação - Distribuiçăo uniforme 2. Aspersor - Otimização

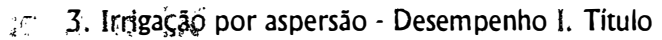

CDD $\quad 631.7$ 


\section{OTIMIZAÇÃO DO USO DE UM ASPERSOR TIPO CANHÃO EM FUNÇÃO DAS CARACTERÍSTICAS OPERACIONAIS E VELOCIDADE MÉDIA DO VENTO}

CLÁUDIO TOMAZELA

Aprovada em 09.04.96

Comissão julgadora:

Prof. Dr. Tarlei Arriel Botrel ESALQ/USP

Prof. Dr. Antonio Fernando Lordelo Olitta ESALQ/USP

Prof. Dr. Nilson Augusto Vila Nova ESALQ/USP

Prof. Dr. Vital Pedro da Silva Paz UFPB Prof. Dr. Fernando Braz Tangerino Hernandez

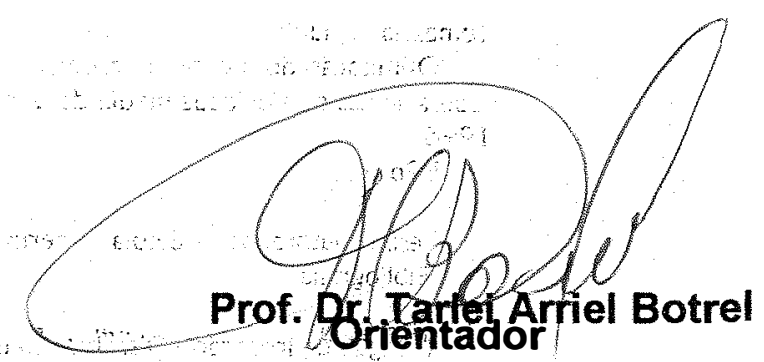


À minha esposa MIRIAM

OFEREÇO

Àqueles que de alguma maneira me apoiaram e auxiliaram direta ou indiretamente na elaboração deste trabalho.

DEDICO 


\section{AGRADECIMENTOS}

À Escola Superior de Agricultura "Luiz de Queiroz", através do Departamento de Engenharia Rural, pela oportunidade de realizar este trabalho;

Ao Conselho Nacional de Desenvolvimento Cientifico e Tecnológico (CNPq), pelo auxilio financeiro durante a realização do curso;

Aos professores Dr. Tarlei Arriel Botrel e José Antonio Frizzone, pela amizade, apoio e orientação durante o curso;

Ao professor Dr. Antonio Fernando Lordelo Olitta, pela amizade, apoio e incentivo à pesquisa em irrigação e drenagem;

Ao grande amigo e professor Dr. Nilson Augusto Villa Nova, pela amizade, ensinamentos e inestimável colaboração;

Ao amigo pesquisador Dr. Hermano Vaz Arruda pela valiosa colaboração e pelas sugestões apresentadas nas análises estatísticas;

Aos amigos professores Antonio Roberto Pereira e Marcos Milan, pelo apoio dado no curso e pelas sugestões oferecidas;

Ao Engenheiro Agrônomo Anderson Soares Pereira, pela amizade e auxilio nos trabalhos;

Aos proprietários rurais que me deram oportunidade de entender um pouco mais sobre os equipamento de irrigação;

A todos os professores que tiveram participação em minha formação profissional, desde os primeiros passos no curso primário;

À prof ${ }^{a}$ Cimara Pereira Prada pela revisão em português;

A todos aqueles que direta ou indiretamente contribuiram para que este trabalho fosse realizado. 


\section{SUMÁRIO}

Página

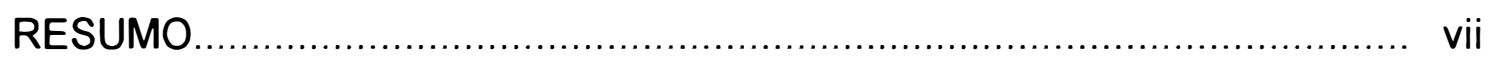

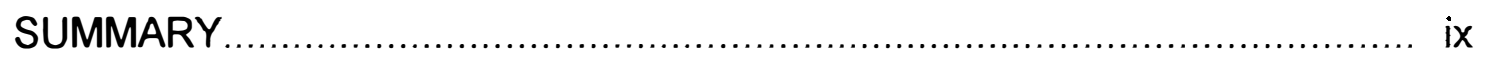

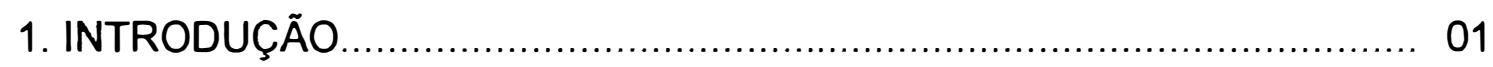

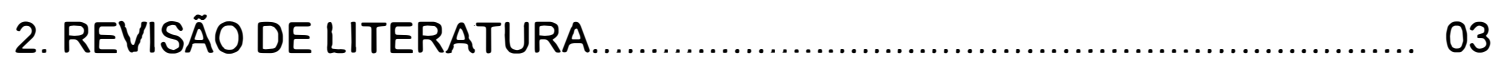

2.1 Fatores que influenciam a distribuição de água nos sistemas de irrigação por aspersão................................................................. 03

2.1.1 Fatores ambientais ........................................................... 03

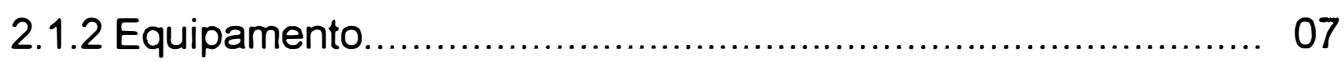

2.1.3 Fatores operacionais................................................ 10

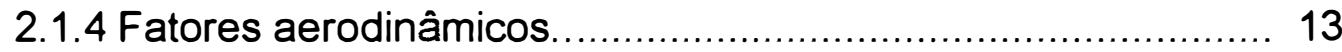

2.2 Uniformidade de distribuição de água............................................ 14

2.2.1 Medidas de uniformidade ............................................... 14

2.2.2. Coeficientes de uniformidade.......................................... 16

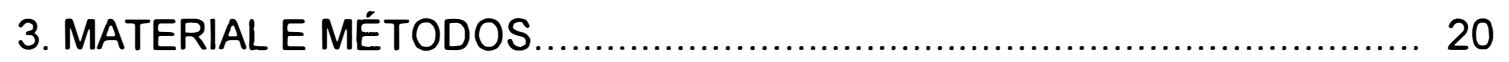

3.1 Caracterização da área experimental.......................................... 20

3.2 Materiais utilizados nos ensaios ............................................. 20

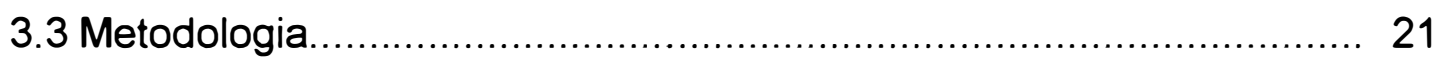

3.3.1 Caracterização dos ensaios.............................................. 21

3.3.2 Determinações de pressão e vazão dos aspersores.............. 23

3.3.3 Determinação da velocidade do vento e da evaporação de

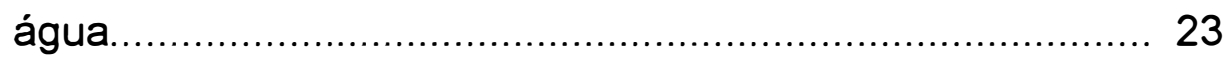

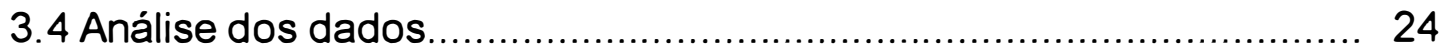


3.4.1 Distribuição de água

3.4.1.1 Análise de regressão múltipla para a uniformidade de distribuição de água................................................. 25

3.4.2 Velocidade do vento .................................................... 26

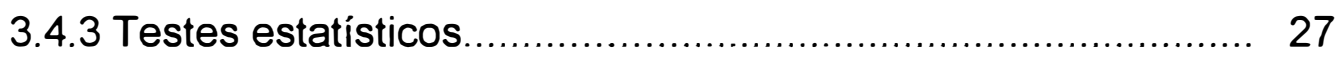

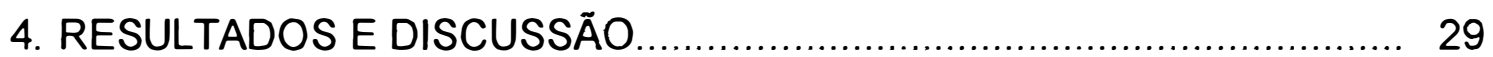

4.1 Análise da uniformidade de distribuição de água............................. 29

4.2 Modelo de regressão linear para a uniformidade ............................ 35

4.2.1 Testes estatísticos....................................................... 37

4.2.1.1 Testes de siginificância dos parâmetros do modelo polinomial ajustado............................................... 37

4.2.1.2 Teste do grau de adequação do CUC ....................... 40

4.2.1.3 Aplicação do modelo ajustado.................................. 42

4.2.1.3.1 Avaliação do modelo para dimensionamento de sistemas.................. 45

4.1.2.3.2 Aplicação do modelo ajustado para avaliação e redimensionamento de sistemas............................................ 46

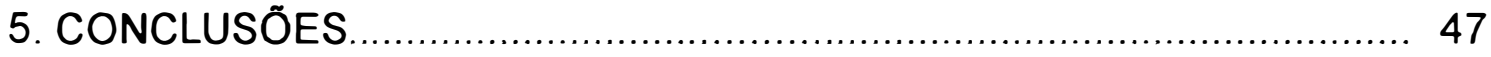

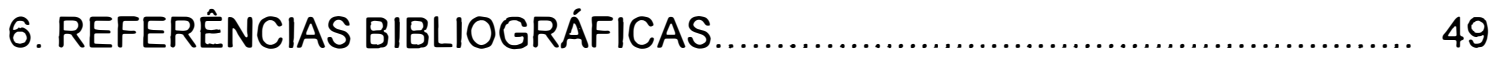

APÊNDICE 1: llustração das superfícies de resposta, obtidas com o uso do programa CATCH3D, versão 4.21 . 


\title{
OTIMIZAÇÃO DO USO DE UM ASPERSOR TIPO CANHÃO EM FUNÇÃO DAS CARACTERÍSTICAS OPERACIONAIS E VELOCIDADE MÉDIA DO VENTO
}

\author{
Autor: CLÁUDIO TOMAZELA \\ Orientador: Prof. Dr. TARLEI ARRIEL BOTREL
}

\section{RESUMO}

Este trabalho teve como objetivo a otimização do uso de um aspersor rotativo tipo canhão, considerando-se os parâmetros que têm influência direta na uniformidade de distribuição de água, como ângulo de trajetória do jato, pressão de operação, espaçamento entre aspersores e entre linhas laterais (área molhada) e velocidade média do vento.

A uniformidade de distribuição de água foi avaliada pelo coeficiente de uniformidade de Christiansen (CUC). Com esses dados foram feitas várias simulações de sobreposições de lâmina de água, pela combinação de espaçamentos dos aspersores, a partir do perfil de distribuição de um aspersor operando isoladamente.

Buscou-se, através do levantamento de uma série de dados de campo, envolvendo diferentes combinações de ângulos de trajetória do jato $\left(18^{\circ}\right.$ a $30^{\circ}$, com subdivisões de $3^{\circ}$ ), pressões de operação (300 a 500 $\mathrm{kPa}$, com subdivisões de $50 \mathrm{kPa})$ e áreas molhadas $(900,1080,1296,1512 \mathrm{e}$ $\left.1764 \mathrm{~m}^{2}\right)$, representar várias condições de vento $(0$ a $2,75 \mathrm{~m} / \mathrm{s})$ e, dessa maneira, ajustar um modelo que melhor representasse as interações entre esses dados para a determinação do CUC.

O modelo de ajuste obtido foi o polinomial quadrático e os resultados mostram que a uniformidade de distribuição, representada pelo 
CUC, é estimada adequadamente. Os parâmetros estudados no modelo ajustado foram significativos em nível de $1 \%$ de probabilidade.

De maneira geral, pôde ser observado que o CUC sofreu redução, à medida que se aumentaram os espaçamentos entre aspersores, e que, quanto maior o ângulo de trajetória, menores foram os valores de vento que admitiram a obtenção de $C U C \geq 80 \%$, independentemente da pressão utilizada e do espaçamento considerado.

Para dimensionamento de novos projetos, o modelo ajustado permite otimizar a instalação em termos de ângulo de trajetória, pressão de operação e espaçamento (área molhada), sendo conhecida a condição de velocidade média de vento na região. Por outro lado, para projetos existentes, quando há a possibilidade de mudanças de espaçamento elou pressão, pode-se otimizar a instalação, conhecendo-se a velocidade média do vento na região. 


\title{
OPTIMIZATION OF A GUN SPRINKLER SYSTEM TAKING IN ACCOUNT THE OPERATIONAL CHARACTERISTICS AND AVERAGE WIND SPEED
}

\author{
Author: CLÁUDIO TOMAZELA \\ Adviser: Prof. Dr. TARLEI ARRIEL BOTREL
}

\section{SUMMARY}

The aim of this work was to optimize the performance of a gun sprinkler taking in account the variables that have influence in the water distribution characteristics: trajectory angle, space between sprinklers, pressure and wind velocity.

The water distribution uniformity of the sprinkler was evaluated using the uniformity coefficient of Christiansen (UC). With these data, simulations were performed adopting differents spaces between sprinklers in order to determinate the water distribution uniformity, from a single sprikler.

Simulations were performed with wind velocities from 0 to $2,75 \mathrm{~m} / \mathrm{s}$ at different pressures ( $300 \mathrm{kPa}$ to $500 \mathrm{kPa}$ at $50 \mathrm{kPa}$ intervals), wet areas $\left(900,1080,1296,1512\right.$ and $\left.1764 \mathrm{~m}^{2}\right)$ and trajectory angles $\left(18^{\circ}\right.$ to $30^{\circ}$, with subdivision of $3^{0}$ ).

The results indicated that the adjusted model fits well the UC and was influenced significatively at a level of $1 \%$ of probability by spacing combinations, pressure, trajectory angle and wind velocity.

In general, the UC suffered a reduction as the space increases. If the jet angle increases, there will be a restriction to the wind velocity to keep the UC equal or above $80 \%$, regardless of pressure and space. 
Using this methodology, it is possible to perform the optimization of new irrigations systems for space, trajectory angle and pressure when the average wind velocity for the region is known. On the other hand, for irrigation systems which are already in use, when exists the possibility to make changes in space and/or pressure, it is possible to optimize the water application taking in account the average wind velocity. 


\section{INTRODUÇÃO}

A maneira como a água é distribuída sobre a área irrigada deve ser considerada quando se procura caracterizar o desempenho dos sistemas de irrigação em condições de campo. A desuniformidade na distribuição de água pode acarretar perdas econômicas devido a excesso ou déficit de água em determinadas partes da área. Se a água necessária ao crescimento das plantas não for aplicada de maneira uniforme, as produções serão afetadas diretamente, principalmente nas regiões onde a produção agrícola depende sobretudo da eficiência da irrigação. Em muitos casos, a água disponivel à irrigação é limitada e, assim sendo, os sistemas de irrigação devem aplicar a água de maneira que as plantas possam utilizá-la eficientemente. Em contrapartida, o custo para se projetar um sistema operando em condições de melhor uniformidade é geralmente maior.

HART \& HEERMANN (1976) citam que, para selecionar um sistema de irrigação por aspersão, deve-se considerar o ótimo retorno em unidades monetárias, em culturas, em produtividade, em produção por unidade de água aplicada e em produção por unidade de degradação ambiental.

Esses autores também comentam que, como aspecto importante na determinação do retorno, está o sistema de distribuição de água no campo, o qual afeta diretamente a produção. Pequenas porções de área superirrigada podem resultar em poluição do lençol freático e diretamente causar perda de dinheiro com os nutrientes lixiviados.

Em se tratando do uso de aspersores rotativos na irrigação por aspersão, uma das características desejáveis, sob diferentes condições operacionais, é proporcionar um determinado alcance no jato, de modo a manter elevada a uniformidade de distribuição de água. Os principais 
problemas durante as irrigações são o fator vento (HART \& HEERMANN, 1976), o qual varia em intensidade e direção aleatoriamente e o ângulo do jato, na saída do bocal, em relação à horizontal (HEEMSTRA et alii, 1983).

Dentre os inúmeros fatores que afetam as características de funcionamento e o desempenho de aspersores rotativos, destacam-se a forma $e$ as dimensões dos bocais. Os principais tipos de bocais comercialmente disponiveis nos aspersores nacionais são os convergentes e os anéis. Tais formas modificam acentuadamente o comportamento das linhas de fluxo na saída do bocal, alterando, por conseguinte, as características de funcionamento e distribuição de água nos aspersores.

Com base no exposto, este trabalho teve como objetivo otimizar o uso de um aspersor tipo canhão, utilizado para irrigação, em função das seguintes características operacionais: ângulo de trajetória do jato, pressão de operação, espaçamento entre aspersores e entre linhas laterais (área molhada) e a velocidade média do vento, baseando-se na uniformidade de distribuição de água. 


\section{REVISÃO DE LITERATURA}

\subsection{Fatores que influenciam a distribuição de água de sistemas de irrigação por aspersão}

Segundo HART \& HEERMANN (1976); BRANSCHEID \& HART (1968); PAIR et alii (1968) e SOLOMON (1979), os fatores que afetam a distribuição de água num sistema de irrigação por aspersão podem ser divididos basicamente em ambientais, de equipamento, operacionais e aerodinâmicos.

\subsubsection{Fatores ambientais}

Incluem-se nesse grupo a velocidade e direção do vento, a temperatura e a umidade relativa do ar.

É importante notar que esses fatores variam durante uma irrigação ou até mesmo durante um ensaio de aspersores. As experiências têm mostrado que a magnitude e a freqüência dessas variações, especialmente a velocidade e a direção do vento, podem ser tão importantes quanto os valores médios dessas variáveis. Além disso, um único valor de uma dessas variáveis, mesmo num dado instante de tempo, pode não ser suficiente para descrevelos adequadamente. Como exemplo, a velocidade do vento pode ser mais bem definida em um dado local e tempo, se relacionada com sua altura acima do solo.

LOPEZ (1975) e BERNARDO (1989) citam o vento, a umidade relativa e a temperatura do ar como os principais fatores ambientais 
que influenciam o uso da irrigação por aspersão. O vento altera a uniformidade de distribuição de água dos aspersores e, juntamente com a temperatura e a umidade relativa do ar, influi nas perdas por evaporação.

$O$ efeito do vento pode ser reduzido quando se diminuem os espaçamentos dos aspersores, tanto ao longo das linhas laterais como entre elas. Sob condições de vento, a área molhada sofre um desvio na forma, alongando-se no sentido da ação do vento e diminuindo-se no sentido oposto. A grandeza da distorção no perfil de distribuição é função da velocidade do vento e do tamanho das gotas de água. Velocidades mais elevadas e gotas menores favorecem a distorção do perfil, resultando em menor uniformidade (FRIZZONE, 1992). Para ventos com velocidade variando de 0 a $2,2 \mathrm{~m} / \mathrm{s}$, a uniformidade de distribuição de água é pouco afetada e entre 2,2 a 3,61m/s resultam em valores aceitáveis de uniformidade de distribuição (WITHERS \& WIPOND, 1977).

PAZ (1990), estudando a influência dos elementos climáticos sobre a uniformidade de distribuição de água de um aspersor individual, com bocais de $4,5 \times 5,5 \mathrm{~mm}$ de diâmetro, concluiu que a velocidade do vento foi o fator que mais influenciou nas perdas de água por evaporação e arrastamento (deriva), seguida da umidade relativa do ar, nas condições estudadas. Em condições de umidade relativa do ar de $40 \%$, temperaturas de $32^{\circ} \mathrm{C}$ e velocidade média do vento em torno de $4,0 \mathrm{~m} / \mathrm{s}$, constatou perdas de água por evaporação e arrastamento pelo vento, de até $40 \%$ do volume aplicado.

ARRUDA (1981), analisando a uniformidade de distribuição de água em sistemas de irrigação por aspersão, concluiu que o espaçamento entre aspersores deve ser reduzido à medida que aumenta a velocidade média do vento. Melhores valores de uniformidade de distribuição foram obtidos com ventos de $0,5 \mathrm{~m} / \mathrm{s}$ e espaçamento de 4 a $6 \mathrm{~m}$ entre aspersores e pressões de operação de 25 a 30 m.c.a.

GOMIDE (1978), usando um aspersor marca Asbrasil, modelo ZED-30, com ângulo de jato de água de $27^{\circ}$ e diâmetro dos bocais de 
$6,0 \times 7,5 \mathrm{~mm}$, em estudo acerca do efeito do espaçamento entre aspersores sobre o coeficiente de uniformidade de Christiansen (CUC), sob diferentes condições de vento, verificou que, para tubo de elevação de $0,5 \mathrm{~m}$, na ausência de vento, o espaçamento de $18 \times 15 \mathrm{~m}$ proporcionou o melhor valor de CUC.

CHRISTIANSEN (1942), estudando as perdas por evaporação na irrigação, concluiu que, nos ensaios realizados no período da tarde, elas atingiram valores entre 10 e $42 \%$, enquanto, nos ensaios realizados no período da manhã, foram de $4 \%$. Observou também que, num aspersor trabalhando isoladamente, as perdas de água podem atingir até $40 \%$, sendo que, por evaporação da água aspergida, são menores que $2 \%$, enquanto as perdas pela evaporação da superfície úmida podem chegar a $15 \%$. Estas foram maiores em dias secos, com ventos fortes e quentes.

As perdas por evaporação, na irrigação por aspersão, podem ser estimadas entre 2 e $8 \%$ do volume de água aplicado. Para sistemas bem dimensionados, é possivel obter-se uma eficiência de aplicação em torno de $85 \%$, podendo ser superior, se o sistema for operado à noite e com ventos fracos. Normalmente a eficiência de aplicação varia entre 70 e $80 \%$ segundo, CHRISTIANSEN (1942); DAVIS (1966) e DAKER (1983).

SHULL \& DYLLA (1976), estudando os efeitos do vento no padrão de aplicação de água, a partir de um aspersor canhão, concluíram que, com o aumento no diâmetro dos bocais, a água foi projetada a maiores distâncias, tornando o padrão de aplicação mais distorcivel pelo vento. A uniformidade de aplicação diminuiu com o aumento da velocidade do vento e da pressão de operação do aspersor. Quanto ao perfil de distribuição da água, verificaram um maior efeito do vento em relação à pressão de operação.

SEGINER (1969) estudou o efeito da variação na direção e velocidade do vento sobre a distribuição de água em irrigação por aspersão. Os dados coletados no campo foram baseados no modelo de distribuição de apenas um aspersor para diferentes pressões nos bocais, direção e velocidade de vento. Verificou que as variações na direção e velocidade do vento tiveram influência significativa sobre a distribuição da água, 
principalmente quando a linha de aspersores foi instalada transversalmente à direção do vento.

FROST \& SCHWALEN (1960), em seus estudos sobre a evaporação durante a irrigação por aspersão, comentam que, considerando as perdas de água aspergida (perdas no ar), a irrigação por aspersão é um eficiente método de aplicação, a menos que as velocidades do vento sejam altas durante os dias secos e clima quente, ou que o sistema não seja adequadamente dimensionado, de maneira que a água não possa ser aplicada uniformemente. Informam os autores que é impossível a obtenção de uma análise completa das perdas por aspersão numa cultura em crescimento, a partir das informações apenas das perdas por evaporação. Se parte da água não pode ser coletada e medida, será totalmente perdida quando o solo está descoberto. Como conclusão de seus estudos, citam que, exceto nos casos de solo nu e/ou altas velocidades de vento, as perdas por evapotranspiração durante as irrigações podem ser desprezadas dos cálculos de perdas na aplicação, uma vez que elas são aproximadamente iguais às perdas por evapotranspiração normal, quando não se está irrigando.

SOLOMON (1979), numa pesquisa sobre a variabilidade dos resultados de testes de coeficientes de uniformidade de aspersores, cita que os valores dos coeficientes de uniformidade são geralmente interpretados como dependentes das variáveis de projeto do sistema (marca, tamanho e tipo do bocal, pressão e espaçamento entre aspersores) e da principal variável, que é a velocidade do vento.

Comenta ainda o autor que muitos outros fatores, além dos citados, podem afetar os resultados do teste, e eles se agrupam em duas categorias: (1) as incertezas devido ao método experimental (volumes de água coletada, pressão de serviço, velocidade do vento, etc.); (2) os métodos de interpretação dos resultados (às vezes citados como idênticos, quando, na verdade, não o são). Como exemplo, cita as diferenças existentes nos valores dos coeficientes de uniformidade para aspersores de mesmo modelo, não 
obstante de diferentes unidades físicas e, portanto, com diferenças na fabricação.

Ainda de acordo com SOLOMON (1979), pequenas diferenças no bocal ou no mecanismo de rotação podem significar resultados diferentes na irrigação, assim que a água deixa o aspersor. Por outro lado, as condições climáticas são responsáveis pela maioria das diferenças existentes nos resultados dos testes de uniformidade, e pelo menos três dessas variáveis não são incluídas entre os cinco principais fatores citados, quando se refere aos dados dos coeficientes de uniformidade. São elas: direção e velocidade do vento e demanda evaporativa durante os testes. Para uma dada velocidade de vento, as mudanças na sua direção transformam a orientação do padrão de aspersão, com relação à lateral de aspersores e, dessa maneira, afetam o coeficiente de uniformidade.

Young ${ }^{1}$, citado por SOLOMON (1979), discute a influência da variabilidade do vento sobre o coeficiente de uniformidade na irrigação. $A$ variabilidade na velocidade e direção do vento, considerando-se uma dada velocidade média, é uma função do local e da hora do dia em que os testes são conduzidos, bem como de sua duração.

SOLOMON (1979) cita que a evaporação dos coletores, durante o período em que o aspersor está sendo operado e durante o tempo em que os volumes estão sendo medidos, apresenta algum efeito, não estritamente proporcional ao volume de água obtido em cada coletor.

\subsubsection{Equipamento}

Os fatores referentes ao equipamento incluem marca $e$ modelo do aspersor, tamanho do bocal, ângulo de saída do jato, velocidade angular e condições hidráulicas aproximadas do aspersor.

YOUNG. T. L. Sprinkler performance prediction when operated in unstead wind. Logan, UTAH.

1973. UTAH State University. (tese de Mestrado). 
Os fabricantes dispõem de diversos modelos e tamanhos de aspersores, com bocais de variados diâmetros, os quais, em função da presssão de serviço, fornecerão a vazão, o alcance do jato, o tipo de precipitação e a distribuição característicos (KELLER \& BLIESNER, 1990).

JAMES (1988) cita que o volume e a taxa de precipitação de água sob o aspersor normalmente variam com a distância radial em relação ao mesmo. O padrão dessa variação é chamado de padrão de distribuição, sendo característico para uma dada pressão e geometria de bocal. Aspersores que trabalham com pressões baixas apresentam padrão de distribuição não uniforme, depositando mais água próximo à borda externa. 0 padrão de distribuição pode ser controlado pela geometria dos bocais (tamanho, forma e ângulo), combinação de bocais e pressão de serviço. Para sua caracterização, são necessários três índices: taxa de aplicação, alcance e forma do padrão (SOLOMON \& BEZDEK, 1980).

Outro fator que pode afetar a distribuição de água dos aspersores é a velocidade de rotação dos mesmos. CHRISTIANSEN (1942) afirma que a variação da velocidade de rotação em cada quadrante foi responsável pela desuniformidade de distribuição em muitos testes realizados. Isto ocorre devido a variações na friç̧ão das partes móveis, quando o aspersor está em diferentes posições. Uma vez que a força de movimento é relativamente constante, a variação na velocidade de rotação resulta da variação da resistência friccional. Sob condições adequadas de pressão, a não uniformidade devido à friç̧ão tem pouco efeito na velocidade de rotação.

Para alta velocidade de rotação, foi observada uma redução na área abrangida pelo aspersor e um incremento na taxa de aplicação. Nesses casos, os aspersores devem ser dispostos em espaçamento menor para assegurar a mesma uniformidade de distribuição da água.

Os formatos dos bocais são também considerados elementos importantes na uniformidade de distribuição dos aspersores. BILANSKI \& KIDDER (1958) analisaram diversos formatos de bocais e verificaram que os do tipo triangular seguidos dos retangulares, apresentaram 
maior quebra do jato e melhor padrão de distribuição do que os circulares. A orientação vertical do maior eixo do bocal retangular mostrou-se mais adequada, pois esse tipo de dispersão resultou em perfil de distribuição mais uniforme do que do que o da orientação horizontal. Devido à turbulência que ocorre, os bocais não circulares podem ser eficientes em baixas pressões de operação, originando padrões de distribuição aceitáveis (DADIAO \& WALLENDER, 1985).

HEEMSTRA et alii (1983), em seus estudos sobre a avaliação do desempenho de aspersores rotativos semelhantes, com variação no ângulo de saída do jato de $24^{\circ}$ e $30^{\circ}$, concluíram que, sob condições de vento fraco, inferior a $0,14 \mathrm{~m} / \mathrm{s}$, o ângulo de $30^{\circ}$ proporcionou melhor uniformidade de distribuição de água, em diversas condições de espaçamento entre aspersores. Para ventos médios mais elevados, durante o período de ensaio, como os superiores a $1,94 \mathrm{~m} / \mathrm{s}$, a uniformidade de distribuição de água com o ângulo de $24^{\circ}$ foi superior à de $30^{\circ}$, para condições de maiores espaçamentos entre os aspersores. A redução da uniformidade, com o aumento da velocidade média do vento, foi mais pronunciada com o ângulo de $30^{\circ}$ que com o de $24^{\circ}$.

BILANSKI \& KIDDER (1958), em estudos conduzidos em ambiente controlado, para eliminar variáveis climáticas, revelaram que 0 aumento no ângulo de inclinação do bocal, entre 10 e $35^{\circ}$, em intervalos de $5^{\circ}$, aumentou o alcance do jato e reduziu a quantidade de água coletada no ponto de máxima precipitação. A razão desse decréscimo foi sendo reduzida à medida que aumentava o ângulo, cujo efeito foi muito mais crítico a baixas que a elevadas pressões. Também observaram que, nas áreas próximas ao aspersor, não se verificaram diferenças na quantidade de água coletada nos diversos ângulos estudados. 


\subsubsection{Fatores operacionais}

Incluem a pressão do bocal, o espaçamento entre os aspersores e entre as linhas laterais, a altura de elevação do aspersor e o tempo de irrigação. São fatores que podem ser convenientemente alterados pelo irrigante, principalmente nos sistemas móveis. Assim sendo, as condições operacionais podem incluir variações no posicionamento dos sistemas móveis.

FRIZZONE (1992) descreve a função da pressão de operação dos bocais dos aspersores. No bocal, a carga de pressão disponivel é transformada em carga de velocidade. O jato é lançado, através do bocal, a uma dada velocidade inicial, pulveriza-se em gotas de diferentes tamanhos, as quais se precipitam em uma dada área ao redor do aspersor. Dessa maneira, a área molhada pelo aspersor e a distribuição da água sobre ela dependem principalmente da pressão de operação, do tipo e do diâmetro dos bocais, bem como do ângulo de saída do jato.

Comenta ainda o autor que, para um dado diâmetro de bocal, as pressões elevadas ocasionam uma pulverização maior do jato de água, resultando em gotas de pequenos diâmetros, que, por apresentarem menor energia cinética e um atrito com o ar proporcionalmente maior, resultam num alcance final reduzido do jato. Assim, para espaçamentos grandes entre aspersores, deve ocorrer uma maior concentração de água próximo ao aspersor, induzindo a menores valores de uniformidade. Por outro lado, as pressões baixas fazem com que o jato emergente do bocal se mantenha mais integro, resultando em gotas de maior diâmetro, que, por apresentarem maior energia cinética e menor atrito com o ar, alcançam maiores distâncias.

De acordo com CHRISTIANSEN (1942) e DAKER (1976), é importante o estabelecimento da pressão ideal de funcionamento do aspersor, para possibilitar melhor distribuição de água. Reduzindo-se a pressão, a velocidade da água na saída do bocal diminui e a resistência do ar passa a não ser suficiente para fragmentar o jato em pequenas gotas, em forma de chuva. Todavia o jato de água pode ficar com alcance ligeiramente maior do 
que o esperado e cair pesadamente sobre o solo, ficando a parte intermediária do terreno subirrigada. Para pressões acima da especificada, ocorre o inverso: o jato adquire maior velocidade e encontra grande resistência do ar; daí fragmentar-se em gotas e precipitar-se em forma de chuva muito fina, mais nas proximidades do aspersor, ficando a parte externa do círculo subirrigada.

CHRISTIANSEN (1942) estudou o efeito da baixa pressão, da velocidade do vento e da velocidade de rotação (intensidade e variação) nos modelos de distribuição de água. Com relação ao efeito da alta velocidade de rotação, notou uma redução da área abrangida pelo aspersor, a qual incrementou a taxa de aplicação. Assim, quando a velocidade de rotação é elevada, os aspersores devem ser dispostos em um espaçamento menor, para assegurar a mesma uniformidade de distribuição.

Segundo OLITTA (1978), a combinação ideal entre a pressão e o diâmetro do bocal resultará na distribuição correta da água, com tamanho de gotas adequado ao tipo de solo e de planta e ao alcance do jato. Quando maiores que $4 \mathrm{~mm}$, em diâmetro, as gotas tendem a danificar as partes tenras das plantas e a formar incrustações na superfície de determinados tipos de solos. Gotas de diâmetros abaixo de $1 \mathrm{~mm}$ são facilmente levadas pelo vento. Dessa forma, aspersores de tamanho médio, trabalhando com pressões corretas, devem produzir gotas na faixa de 1 a $4 \mathrm{~mm}$.

COELHO (1990), utilizando o aspersor marca DANTAS, modelo MD 20A, com diâmetros dos bocais de 4,4×2,5mm, estudou o efeito da pressão de operação na uniformidade de distribuição de água, sob diferentes condições de espaçamento. Concluiu que, em espaçamentos reduzidos (6x12m e 12×12m), as pressões maiores (300 e $400 \mathrm{kPa}$ ) dos aspersores, apresentam maiores valores de coeficientes de uniformidade de Christiansen

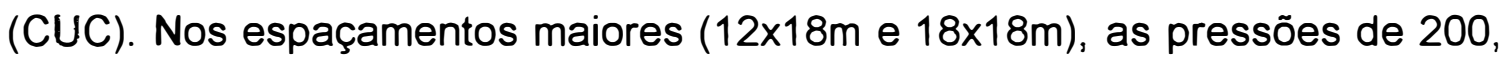
300 e $400 \mathrm{kPa}$ não diferem significativamente quanto aos valores dos coeficientes apresentados.

FRIZZONE (1992), tecendo considerações sobre os trabalhos de COELHO (1990), comenta que, para pressões médias maiores 
(300 e $400 \mathrm{kPa}$ ), em espaçamentos menores (6x12m e 12x18m), os valores de CUC foram melhores, sendo respectivamente de 0,897 e 0,920. Em

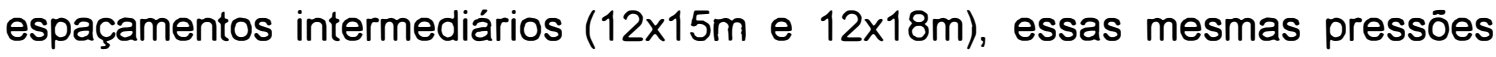
não diferiram quanto aos valores de CUC (valores médios de 0,850 e 0,880, respectivamente). Nos espaçamentos maiores $(18 \times 18 \mathrm{~m}, 18 \times 24 \mathrm{~m}$ e $24 \times 24 \mathrm{~m})$, à pressão de $200 \mathrm{kPa}$, os valores de CUC foram respectivamente de 0,738 , 0,581 e 0,497, não diferindo dos obtidos nas pressōes de 300 e $400 \mathrm{kPa}$.

Quanto às recomendaçōes de espaçamento, elas podem ser feitas com base no diâmetro molhado do aspersor, que é função do diâmetro do bocal e da pressão de serviço (KELLER \& BLIESNER, 1990).

De acordo com BARRETO (1974), para boa uniformidade na distribuição de água, os aspersores devem ser instalados a uma distância que permita sobreposição adequada dos círculos molhados. Fabricantes norteamericanos de aspersores aconselham $100 \%$ de superposição dos jatos, o que equivale a dizer que 0 jato emitido por um aspersor deve atingir 0 aspersor seguinte, enquanto os fabricantes europeus de aspersores recomendam sobreposição de apenas 25 a 30\% de seu raio de alcance.

FRIZZONE (1992) considera que, para se manter uma aceitável uniformidade de distribuição de água, deve haver suficiente sobreposição dos perfis de distribuição entre aspersores adjacentes. $O$ grau de sobreposição depende das características do perfil de distribuição que, por sua vez, é função do tipo de aspersor, da pressão de operação e das condiçōes de vento. O mesmo autor, discorrendo sobre a influência da altura de elevação do aspersor, cita que os tubos de elevação são utilizados para manter o aspersor a uma altura adequada em relação à copa das plantas e para eliminar a turbulência da água, quando derivada da linha lateral para o aspersor, assegurando uma irrigação mais uniforme e eficiente. O aspersor deve estar perpendicular à superfície do solo e bem acoplado à linha lateral.

GOMIDE (1978), analisando a influência da altura do tubo de elevação no coeficiente de uniformidade, para diferentes velocidades de 
vento, cita que foi observado aumento linear no valor do CUC, em todas as velocidades de vento estudadas (em média, $2,2 \%$ para cada metro de altura).

\subsubsection{Fatores aerodinâmicos}

Os fatores aerodinâmicos incluem as interações das gotas de água, a partir dos aspersores adjacentes, e as massas de ar que se deslocam através do jato de água dos aspersores.

ROUSE et alii (1952) descreveram de maneira detalhada a seqüência de quebra do jato de água a partir de um bocal. Mostram que a ação do ar passa a ter efeito sobre $o$ jato de água, somente após a superfície do mesmo ter sido suficientemente interrompida, quando se produz uma apreciável forma de resistência. Esta é proporcional a aproximadamente o quadrado da velocidade da água e à área da secção transversal de expansão do jato. Quanto mais água for carreada lateralmente para fora do fluxo central do jato, mais rapidamente este é retardado, em sua trajetória longitudinal, pelo ar circundante, embora continue se espalhando lateralmente, apenas reduzindo levemente sua velocidade. A parte externa do jato forma imediatamente gotas que caem pulverizadas e a sua porção central mostra gotas se desintegrando pelo ar. Isso ocorre porque o jato originalmente intacto, mas turbulento no centro, é transformado, ao longo da sua trajetória, em uma mistura expansiva de ar e gotas dispersas de água, as quais caminham a uma velocidade já decrescente, ainda que trazendo um volume crescente de ar em movimento. Verifica-se, portanto, que essa quebra é originada a partir da turbulência nas laterais do jato.

MERRINGTON \& RICHARDSON (1947) mostram que os diâmetros médios das gotas, formadas na quebra do jato, são inversamente proporcionais à velocidade relativa entre o jato e $\mathrm{o}$ ar que o circunda. A água próxima à periferia do jato produz pequenas gotas, ao passo que a água mais próxima ao núcleo do jato, por possuir menor velocidade relativa em relação 
ao ar, produz gotas maiores. No centro do jato, existe uma mistura de ar e água, que se deslocam em velocidades semelhantes.

BERNUTH \& GILLEY (1984) comentam que, para o caso dos aspersores de impacto, além da quebra das gotas devido à turbulência dos limites do fluxo, ocorre a ação do braço oscilante, que se choca com o jato. Assim, as gotas formam-se pela energia do choque do braço e pelo consequente movimento repentino do jato. Com relação a isso, KOHL (1974) cita que, em iguais condições de operação de um bocal, um jato de menor diâmetro tende a se separar, e o ar penetrará no seu interior mais rapidamente do que em um bocal maior. Dessa maneira, ocorrerá maior diferencial de velocidade entre a água e $\mathrm{o}$ ar, maior espalhamento do jato e, portanto, a formação de gotas menores.

\subsection{Uniformidade de distribuição de água}

\subsubsection{Medidas de uniformidade}

Após definido o tipo de aspersor a ser usado no sistema de irrigação, com base nas limitações de pressão, na intensidade de precipitação, nas necessidades hídricas da cultura e na disponibilidade de mão de obra, o passo seguinte é a determinação do espaçamento entre aspersores, da pressão de serviço e do diâmetro dos bocais; o objetivo é uma ótima aplicação de água com maior grau de uniformidade de distribuição, o que depende primariamente do perfil de distribuição de água e do espaçamento entre os aspersores (ESTADOS UNIDOS, 1968).

De acordo com FRIZZONE (1992), as medidas de uniformidade expressam a variabilidade da lâmina de irrigação aplicada na superfície do solo e a forma usual de se obter essa variabilidade é através de medidas de dispersão, expressas de forma adimensional pela comparação com o valor médio. 
HART (1961) cita dois tipos básicos de ensaio de distribuição espacial de água, a partir de aspersores, sendo que o primeiro consta de um ensaio com vários aspersores operando ao mesmo tempo, dentro do espaçamento estudado. Nesse caso, as precipitações obtidas nos diversos coletores da área amostrada são consideradas diretamente nos cálculos de algum tipo de coeficiente de uniformidade. A segunda maneira de se ensaiarem os aspersores é baseada em testes de campo envolvendo um único aspersor; as precipitações obtidas nos coletores são sobrepostas segundo uma lógica matricial, em que se pode fazer a simulação de diversos espaçamentos entre os aspersores $e$, por meio dos coeficientes de uniformidade calculados, verificar qual deles é o mais eficiente. A principal vantagem desse método é requerer menos tempo para sua realização.

BRANSCHEID \& HART (1968) utilizaram-se de uma amostragem em malha de coletores, para comparação de testes entre um único aspersor e uma linha lateral com treze aspersores espaçados em $9 \mathrm{~m}$. Como conclusão, citam que o procedimento de se fazer a sobreposição entre esses dados e os de um único aspersor é perfeitamente válido.

SATTO (1978) faz citações de ensaios no campus da Escola de Engenharia de São Carlos com um único aspersor e na faculdade de Agronomia de Jaboticabal, com quatro aspersores, sendo que os coletores estavam dispostos em malha. Concluiu que os ensaios realizados com um único aspersor são os mais recomendados, permitindo a geração de vários dados de lâminas sobrepostas, para cada espaçamento, com o uso de computador.

DAVIS (1966), utilizando-se de uma amostragem em malha de coletores, realizou um aprofundado estudo sobre a densidade de coletores em campo de ensaio. Pelos resultados obtidos, ficou demonstrado que, para sistemas com boa uniformidade de aplicação, cada coletor não deve representar mais que $6,7 \%$ da área total de ensaio. Por outro lado, em sistemas com baixa uniformidade, cada coletor deve representar no máximo $2,5 \%$ da área ensaiada. 
COLOMBO et alii (1983) comentam, em trabalho sobre espaçamento entre coletores em estudos de distribuição de água de aspersores, usando-se um único aspersor, que a área definida por um coletor pode representar até cerca de $6 \%$ da área de sobreposição entre os aspersores, sem comprometer a representatividade dos resultados de distribuição.

\subsubsection{Coeficientes de uniformidade}

Para se recomendar um sistema de irrigação, normalmente recai-se sobre a análise de uniformidade dos sistemas, dentro de um padrão de aspersores sobrepostos. Os padrões de distribuição da aspersão são então comparados com outros, através de coeficientes calculados por meio dos dados de precipitação em coletores.

Os testes deverão ser conduzidos em condições de campo, de preferência em condições climáticas semelhantes àquelas onde os aspersores testados serão usados. De acordo com SOLOMON (1979), técnicas para avaliar essa uniformidade, tais como medidas do volume de água em coletores distribuídos no padrão do aspersor, têm sido desenvolvidas e extensivamente utilizadas. A uniformidade tem sido caracterizada, usando-se os volumes obtidos em coletores para o cálculo do coeficiente de uniformidade de Christiansen, do coeficiente de variação, da uniformidade de distribuição dos $25 \%$ menores volumes obtidos na área e outros parâmetros mais. Tais técnicas proporcionam bases quantitativas para comparar 0 desempenho relativo dos diferentes sistemas.

O mais conhecido e largamente utilizado em irrigação por aspersão é o coeficiente de uniformidade proposto por CHRISTIANSEN (1942). Seu uso freqüente é devido à facilidade maior nos cálculos e na adoção em massa, o que o tornou um parâmetro de comparação entre um trabalho e outro. A expressão que representa o coeficiente de uniformidade de Christiansen (CUC) é: 


$$
C U C=\left[1-\frac{\sum_{I=}^{n}|X i-X m|}{n^{*} X m}\right] 100
$$

em que

CUC: coeficiente de uniformidade de Christiansen, em \%;

$X m$ : lâmina ou volume médio coletado, em $\mathrm{mm}$;

$X i$ : lâmina ou volume coletado no i-ésimo coletor, em mm;

$n$ : número de observações.

O CUC adota o desvio médio como medida de dispersão. $O$ desvio médio corresponde à média aritmética do valor absoluto da diferença entre cada lâmina de irrigação aplicada e a lâmina média, isto é:

$$
d=\frac{1}{n} \sum_{i=1}^{n}|Y i-Y m|
$$

em que

d: desvio médio das lâminas coletadas, em mm;

yi: lâmina aplicada no coletor i, em mm;

ym: lâmina média coletada, em mm

n: número do i-ésimo coletor.

De acordo com FRIZZONE (1992), em geral, o valor mínimo aceitável desse coeficiente é de $80 \%$. Valores menores podem ser admitidos se a precipitação pluvial tiver um valor significativo durante a estação de cultivo.

Utilizando o desvio padrão (s) como a medida de dispersão, WILCOX \& SWAILES (1947) propuseram outro coeficiente de uniformidade, denominado coeficiente de uniformidade estatística, descrito pela expressão:

$$
C W S=\left[1-\left(\frac{s}{X m}\right)\right] 100
$$

em que

CWS: coeficiente de Wilcox e Swailes, em \%; 
S: desvio padrão das lâminas ou volumes coletados, em mm ou mi; $X m$ : lâmina ou volume médio precipitado no coletor, em $\mathrm{mm}$ ou $\mathrm{ml}$.

O valor de $70 \%$ para esse coeficiente foi inicialmente sugerido como o mínimo aceitável, sendo, depois, em função de muitos dados de distribuição, aumentado para 75 a $80 \%$.

Um tratamento estatístico mais apurado do CUC, através do estudo da função normal, que deu um significado físico à uniformidade, levou HART (1961) e HART \& REYNOLDS (1965) a proporem outro coeficiente.

$$
C U H=\left[1-\left(\sqrt{\frac{2}{\Pi}}\right)\left(\frac{s}{X m}\right)\right] 100
$$

em que

CUH: coeficiente de uniformidade de HART, em \%;

s: desvio padrão, em mm;

$X m$ : lâmina média, em $\mathrm{mm}$.

Se a lâmina de água tem distribuição normal, então CUH=CUC, e o desvio padrão das lâminas de irrigação com distribuição normal poderá ser obtido em função do valor de CUC, pela expressão:

$$
S n=\frac{X m(1-C U C)}{0,8}
$$

sendo $S n$ : desvio padrão da amostra com distribuição normal, em mm.

Tendo-se os valores de lâmina média, CUC e uma tabela de distribuição normal, é possível determinar qual porcentagem da área está recebendo certa quantidade de água (FRIZZONE, 1992).

Corry $^{2}$, citado por OLITTA (1978), salienta que o valor do coeficiente de uniformidade é o processo estatístico mais comum para a avaliação de sistemas de irrigação por aspersão e, por convenção, o valor de $80 \%$ é o mínimo aceitável para o desempenho normal do aspersor.

2

CORRY, J. A. Sprinkler system evaluation. Davis, University of California, 1958. 
KERR et alii (1980), em seus estudos de padrões de distribuição de diversos aspersores de jardim, utilizando o CUC para comparar os padrões e determinar a maneira como os vários espaçamentos afetam as características da distribuição, consideraram um valor mínimo aceitável de 70\%, seguindo a prática comum citada por HART \& HEERMANN (1976).

KELLER \& BLIESNER (1990) afirmam que, muito embora o conceito de valor baixo seja relativo, valores de CUC $<75 \%$ são geralmente considerados baixos, mesmo para campos gerais e forrageiras. Para culturas de elevado valor, recomenda-se CUC>84\%.

LETEY et alii (1990) afirmam que o valor de CUC mais elevado que se pode esperar de sistemas com movimentação manual é de $80 \%$. Em condições de vento e projeto inadequado, o CUC pode ser consideravelmente menor, principalmente em condições de campo.

CULVER \& SINKER (1966) tecem comentários sobre o CUC, afirmando que o mesmo não é sensível para representar variações nos padrões de distribuição e sugerem o uso do coeficiente de variação. $O$ próprio CHRISTIANSEN (1942) já havia salientado que o CUC é um coeficiente simples de ser calculado, mas que fornece apenas uma informação relativa da distribuição, não podendo, portanto, ser utilizado diretamente como uma medida de eficiência de aplicação, pois existem outros fatores que influenciam na sua determinação.

SOARES et alii (1991) salientam que o CUC tem grande utilidade na comparação das uniformidades de diferentes equipamentos e condições de operação. Comenta que, apesar das limitações no uso de cada coeficiente, o CUC tem sido eleito, na maior parte dos trabalhos científicos e nos estudos de desenvolvimento de equipamentos das indústrias, tendo, por isso, se tornado bastante popular, ao longo da história da aspersão. 


\section{MATERIAL E MÉTODOS}

\subsection{Caracterização da área experimental}

Os ensaios foram realizados numa área plana e gramada, pertencente ao campo de testes de aspersores do Departamento de Engenharia Rural da Escola Superior de Agricultura "Luiz de Queiroz", da Universidade de São Paulo, situado no município de Piracicaba, estado de São Paulo, cujas coordenadas geográficas são $22^{\circ} 42^{\prime} 30^{\prime \prime}$ de latitude Sul, $47^{\circ}$ 38 ' 00" de longitude Oeste, com altitude média de $576 \mathrm{~m}$.

A captação da água para os ensaios foi feita diretamente de um lago localizado em frente ao Pavilhão de Engenharia da ESALQ, onde estava instalada a unidade de bombeamento.

\subsection{Materiais utilizados nos ensaios}

Para os testes de campo, foram utilizados os seguintes materiais:

a) bomba centrífuga marca FSL, modelo CT $810 / 20,159 \mathrm{~mm}$ de diâmetro do rotor, com rotação de $3.450 \mathrm{rpm}$ acoplada sob chassi metálico a um motor marca BUFALO, com 40 c.v. $(29,44$ kW) de potência nominal, IP-54, II polos;

b) tubulação adutora de $4^{\prime \prime}(100 \mathrm{~mm})$ de diâmetro por $6 \mathrm{~m}$ de comprimento, em aço galvanizado e com comprimento total de $150 \mathrm{~m}$;

c) aspersores marca Asbrasil modelo $\mathrm{ZN}$, com bocais duplos de diâmetros $16,0 \times 6,0 \mathrm{~mm}$ e com ângulos de saída do jato de $18^{\circ}$ a $30^{\circ}$, em subdivisões de $3^{0}$; 
d) medidor de vazão marca CONAUT, modelo 463, para vazões de até $30 \mathrm{~m}^{3} / \mathrm{h}$ e precisão de $0,1 \%$.

e) conversor de sinais CONAUT-474, com constante $\mathrm{K}$ igual a 468;

f) anemômetro totalizador de canecas com "biruta";

g) transdutor de pressão com capacidade para $1000 \mathrm{kPa}$, acoplado a um indicador digital microprocessado, com precisão de $0,1 \%$;

h) cronômetro digital, com precisão de 1/100 s.

i) provetas graduadas em $\mathrm{ml}$, com volume de $250 \mathrm{ml}$ e subdivisão de escala de $1 \mathrm{ml}$;

j) coletor (latas de óleo), com secção de captação de $76,511 \mathrm{~cm}^{2}$.

\subsection{Metodologia}

\subsubsection{Caracterização dos ensaios}

O aspersor canhão foi instalado no centro da área, sobre um tubo de elevação de $1,80 \mathrm{~m}$. Os coletores foram distribuídos ao redor do aspersor, seguindo um esquema reticulado com espaçamento de $6 \times 6 \mathrm{~m}$, conforme metodologia proposta pela norma NBR 8989, da Associação Brasileira de Normas Técnicas (ABNT), que discorre sobre o método para a obtenção e apresentação de dados característicos da distribuição de água de aspersores para irrigação.

O total de coletores instalados na área do ensaio foi de 144 unidades, cobrindo uma área total de $72 \times 72 \mathrm{~m}\left(5.184 \mathrm{~m}^{2}\right)$. A área representativa de cada coletor era de $36 \mathrm{~m}^{2}$. Para uma sobreposição mínima estudada de $30 \times 30 \mathrm{~m}\left(900 \mathrm{~m}^{2}\right)$, essa área representa $4 \%$ da sobreposição, estando em acordo com o valor citado por COLOMBO et alii (1983), que especificam uma área máxima para um coletor de $6 \%$ da área de sobreposição entre os aspersores. Tal valor também está em acordo com o valor citado por DAVIS (1966), com recomendações, no máximo 6,7\% para condições de boa 
uniformidade de distribuição, e 2,5\% para baixas uniformidades, em relação à área de ensaio.

A distância vertical entre o centro do bocal principal e o bordo superior dos coletores foi de $1,50 \mathrm{~m}$. $O$ bordo superior dos coletores estava posicionado horizontalmente, mantendo-se uma distância de $0,30 \mathrm{~m}$ em relação à superfície do solo, a qual estava totalmente vegetada por grama com uma altura de $0,05 \mathrm{~m}$.

Foram estabelecidas 5 (cinco) pressões de operação, procurando-se representar adequadamente a faixa de operação desses aspersores, para verificar o efeito que teria o fator pressão no desempenho do aspersor, em função do ângulo de saída do jato de água. Os valores de pressão adotados foram 300, 350, 400, 450 e $500 \mathrm{kPa}$. Cada uma dessas pressões foi usada para os vários ângulos de saída do jato analisados, quais sejam, $18^{\circ}, 21^{\circ}, 24^{\circ}, 27^{\circ}$ e $30^{\circ}$.

Como os ensaios foram efetuados em dias e horários diferentes, as condições de vento médio obtidas são variadas, tendo-se valores de 0 a $2,75 \mathrm{~m} / \mathrm{s}$, como faixa de vento do ensaio.

O procedimento de execução do ensaio, está descrito a seguir e seu início se dava assim que a pressão estivesse estabilizada.

a) colocação da seção de captação de todos os coletores para baixo;

b) colocação do sistema em funcionamento;

c) ajuste da pressão de operação com o uso de transdutor de pressão, mangueiras poly-flo de $1 / 4$ " e registros de gaveta;

d) medição de vazão do aspersor;

e) colocação dos coletores em posição de captação de água dos aspersores, após o desligamento da bomba;

f) colocação da bomba em operação e início do teste;

g) operação do sistema por 60 minutos;

h) leitura de velocidade e direção do vento, em intervalos de 15 minutos;

i) verificação da pressão e da vazão do aspersor, após transcorrido o tempo de 30 e 60 minutos; 
j) desligamento do sistema. ( $O$ encerramento dos ensaios era feito após o jato de água ter completado o mesmo número de rotações em todas as direções de coletores, a partir de uma radial especificada);

k) medição e leitura do volume coletado em cada coletor, com o uso de proveta graduada em $250 \mathrm{ml}$;

1) anotação dos dados relativos à velocidade e direção do vento durante a realização do ensaio.

\subsubsection{Determinações de pressão e vazão dos aspersores}

Para cada um dos ensaios realizados, foram especificadas as pressões de operação e sua obtenção foi efetuada de acordo com o procedimento a seguir:

a) acionar do conjunto motobomba, com registro de gaveta fechado;

b) zerar os instrumentos de medida instantânea de vazão e pressão do sistema;

c) abrir o registro de gaveta até que a pressão especificada para o ensaio fique estabilizada;

d) anotar em planilha, os valores de leitura obtidos.

Assim que era obtida a estabilização da pressão, os valores de vazão indicados pelo medidor CONAUT eram anotados. Dessa maneira, foram efetuadas as leituras de pressão e vazão no início, meio e final da coleta de água.

\subsubsection{Determinação da velocidade média do vento e da evaporação de água}

As condições de vento que prevaleceram durante os ensaios foram caracterizadas pela velocidade média e direção, calculadas através de determinações efetuadas em intervalos de 15 (quinze) minutos, 
utilizando-se um anemômetro totalizador de canecas e uma "biruta", instalados a 2 (dois) metros de altura em relação ao nivel do solo.

A evaporação da água, verificada durante os periodos de ensaio, foi obtida pela diferença entre os volumes inicial e final da água contida em coletores idênticos aos utilizados nos ensaios de distribuição, com volumes de água semelhantes àqueles correspondentes às lâminas médias coletadas durante os ensaios (estimados a partir da intensidade de precipitação teórica dos aspersores).

\subsection{Análise dos dados}

\subsubsection{Distribuição de água}

Foram determinados os valores dos coeficientes de uniformidade de Christiansen (CUC), fazendo-se uso de simulações das precipitações referentes a 5 (cinco) combinações de espaçamento $(30 \times 30 \mathrm{~m}$, $30 \times 36 \mathrm{~m}, 36 \times 36 \mathrm{~m}, 36 \times 42 \mathrm{~m}$ e $42 \times 42 \mathrm{~m}$, equivalendo respectivamente a 900 , $1080,1296,1512$ e $1764 \mathrm{~m}^{2}$ de área). Foram determinadas essas combinações de espaçamento, por representarem o melhor, quando utilizados esses aspersores. Para isso, foi utilizado o programa aplicativo CATCH3D, versão 4.21, desenvolvido pela Universidade de UTAH (EUA), para cada uma das combinações (ângulo "versus" pressão "versus" espaçamento), a partir dos dados de precipitação sobrepostos.

O programa $\mathrm{CATCH} 3 \mathrm{D}$ permite que sejam feitas combinações de espaçamento entre aspersores nas linhas laterais e entre elas, gerando dados, que obedecem ao princípio de que existem aspersores dispostos de uma forma quadrada ou retangular, previamente especificada. 


\subsubsection{Análise de regressão múltipla para a uniformidade de distribuição de água.}

Os dados obtidos foram ajustados, através do método dos mínimos quadrados, a um modelo polinomial que melhor representasse 0 comportamento dos mesmos, tendo sido, para isso, utilizado o programa QPro da empresa de software Borland, versão 4.0. A análise de regresssão teve como objetivo verificar a influência de alguns parâmetros de projeto (ângulo de trajetória, pressão de operação, área molhada correspondente a cada espaçamento entre aspersores e velocidade média do vento), na uniformidade de distribuição de água, estimada pelo coeficiente de uniformidade de Christiansen (CUC). Para tanto, foi ajustado um modelo polinomial quadrático, da forma:

$$
Y=\beta o+\sum_{i=1}^{4} \beta i X i+\sum_{i=1}^{4} \beta i i X i^{2}+\sum_{i=1}^{4} \sum_{j=1}^{4} \beta i j X i X j
$$

em que

$Y$ : coeficiente de uniformidade de Christiansen

$\beta_{0}$ : coeficiente de intersecção;

$\sum_{i=1}^{4} \beta i X i$ : componentes lineares da equação;

$\sum_{i=1}^{4} \beta i i X i^{2}:$ componentes quadráticos da equação;

$\sum_{i=1}^{4} \sum_{j=1}^{4} \beta i j X i X j$ : componentes das interações lineares;

$X i$ e $X_{j}$ : variáveis ângulo de trajetória $(A)$, pressão de operação $(P)$, área molhada $(E)$ e velocidade média do vento $(V)$.

Procedeu-se também à estimativa dos valores de CUC, a partir do modelo polinomial ajustado, e esses dados foram comparados aos valores de CUC obtidos nas simulações de sobreposição das lâminas. 


\subsubsection{Velocidade do vento}

De posse do modelo polinomial quadrático ajustado para o CUC (eq. 6), foram fixados valores referentes a cada uma das combinações possiveis de ângulo de trajetória, de pressão de operação e de espaçamento entre aspersores e entre linhas laterais (área molhada); também foram obtidas expressões do tipo grau 2, representando os valores de CUC em função da velocidade média do vento, conforme segue:

$$
C U C=a+b V-c V^{2}
$$

em que

CUC: coeficiente de uniformidade de Christiansen;

$\mathrm{V}$ : velocidade média do vento;

a, b e c: parâmetros da equação

Derivando-se cada uma das expressões do tipo eq. (7) obtidas para valores de $\mathrm{CUC} \geq 80 \%$ em relação a vento, e igualando-as a zero, foi possível encontrar os valores de vento que otimizassem os valores de CUC, para as condições dos ensaios. Como as derivações de segunda ordem apresentaram coeficientes negativos, os valores de vento obtidos pelas expressões do tipo da eq. (9) para cada combinação estudada, representavam pontos de máximo. Assim, os coeficientes de uniformidade de Christiansen (CUC) também representavam os máximos valores obtidos pelas expressões do tipo da eq. (9).

O passo seguinte envolveu a fixação de valores de CUC $\geq 80 \%$, seguindo as citações de CHRISTIANSEN (1942), DAVIS (1966), DAKER (1976) e OLITTA (1978), para cada uma das expressões do tipo da eq. (7), obtidas em função das combinações de ângulo, pressão e área molhada e pela derivação dessas em relação às velocidades médias de vento; igualandose cada uma dessas expressões a zero, foram obtidas faixas (limites inferiores e limites superiores) de valores de velocidades médias de vento que admitiriam $\mathrm{CUC} \geq 80 \%$. Com essas faixas de valores de velocidades médias do vento, foram montadas tabelas referentes a cada um dos ângulos de trajetória 
estudados nos ensaios em função da pressão de operação e da área molhada. Essas tabelas foram utilizadas, de maneira prática, para análise e interpretação dos resultados. Nessas mesmas tabelas, foram incluídos os valores máximos de CUC, obtidos pela eq. (7), e seus respectivos valores de velocidade média do vento.

\subsubsection{Testes estatísticos}

O primeiro procedimento referente à parte estatística foi a obtenção dos parâmetros de ajuste da equação de regressão polinomial quadrática. Para isso, foi utilizado o programa QPro, da empresa de Software Borland, versão 4.0 .

Através do teste $T$, foi possivel a verificação da significância das variáveis independentes (A, P, E e V). Com o teste $F$, através da análise de variância, foi verificada a significância da regressão para o todo, bem como para cada parâmetro da equação individualmente.

$O$ segundo procedimento seguido foi $O$ descrito em WILLMOTT (1982), com relação ao teste $d$, onde se procurou verificar o grau de adequação do modelo para a estimativa dos valores de CUC, obtidos pela equação de regressão polinomial quadrática com os valores observados nos testes e simulações. Esse teste reflete o grau ao qual os desvios observados em relação à média correspondem em magnitude e sinal aos desvios previstos em relação a média. Não se trata de uma medida de correlação ou associação no sentido formal, mas uma medida do grau a partir do qual as revisões dos modelos estão livres de erros. O teste $\mathbf{d}$ é uma medida padronizada, a fim de ser facilmente interpretada e possibilitar comparações cruzadas de suas magnitudes para uma variedade de modelos, independentemente de unidades. Seus valores variam entre 0 e 1 , sendo que o valor 1 indica um perfeito acordo entre os valores observados e os estimados e o valor zero indica uma série de desacordos. 
A expressão que indica os valores de $\mathbf{d}$ pode ser representada por

$$
d=\left\{1-\left[\frac{\sum(P i-O i)^{2}}{\sum(|P i|+|O i|)^{2}}\right]\right\}
$$

em que

Pi: valores previstos;

Oi: valores observados;

$\mathrm{P}^{\prime} \mathrm{i}=\mathrm{Pi}-$ Om e O'i = Oi - Om, sendo Om o valor médio das observações. 


\section{RESULTADOS E DISCUSSÃO}

\subsection{Análise da uniformidade de distribuição de água}

Nas tabelas de 1 a 5, são apresentados os resultados dos testes de uniformidade de distribuição de água dos aspersores, obtidos pelo programa CATCH3D, versão 4.21 , conforme procedimentos descritos no item 3.4.1. Incluem-se, portanto, os 5 (cinco) ângulos de trajetória do jato, as 5 (cinco) pressões de operação e as 5 (cinco) combinações de espaçamento entre aspersores e entre linhas laterais (área molhada).

Tabela 1: Valores de CUC para o aspersor $Z N$, com ângulo de trajetória de $18^{\circ}$, em função da pressão e da área molhada, sob diferentes condições de vento.

\begin{tabular}{|c|c|c|c|c|c|c|c|c|}
\hline \multirow{2}{*}{$\begin{array}{c}\text { Pressão } \\
\text { kPa }\end{array}$} & \multirow{2}{*}{$\begin{array}{c}\text { Vazão } \\
\text { l/s }\end{array}$} & \multirow{2}{*}{$\begin{array}{l}\text { Vento } \\
\mathrm{m} / \mathrm{s}\end{array}$} & \multirow{2}{*}{$\begin{array}{c}\text { Direção } \\
\text { P.cardeal }\end{array}$} & \multicolumn{5}{|c|}{ Area molhada $\left(\mathrm{m}^{2}\right)$} \\
\hline & & & & 900 & 1080 & 1296 & 1512 & 1764 \\
\hline 300 & 4,99 & 0,69 & $L$ & 82,1 & 82,3 & 71,8 & 65,5 & 65,1 \\
\hline 300 & 4,99 & 0,06 & -- & 77,1 & 82,0 & 71,8 & 66,3 & 67,4 \\
\hline 350 & 5,29 & 1,47 & $\mathrm{~S}$ & 82,5 & 79,9 & 80,3 & 74,9 & 72,1 \\
\hline 350 & 5,29 & 0,00 & -- & 75,1 & 79,9 & 75,4 & 72,8 & 68,4 \\
\hline 400 & 5,80 & 0,14 & L & 80,8 & 81,5 & 84,1 & 79,5 & 73,1 \\
\hline 400 & 5,80 & 1,08 & $\mathrm{~L}$ & 83,4 & 84,2 & 85,3 & 79,3 & 74,5 \\
\hline 450 & 6,08 & 0,11 & L & 83,6 & 81,2 & 81,3 & 81,7 & 74,4 \\
\hline 450 & 6,08 & 0,08 & L & 80,8 & 78,1 & 79,1 & 73,0 & 68,9 \\
\hline 500 & 6,58 & 0,33 & NE & 83,2 & 82,3 & 83,7 & 79,7 & 74,9 \\
\hline 500 & 6,58 & 0,00 & $\ldots$ & 83,1 & 79,9 & 81,1 & 83,2 & 75,6 \\
\hline
\end{tabular}


Tabela 2: Valores de CUC para o aspersor ZN, com ângulo de trajetória de $21^{\circ}$, em função da pressão e da área molhada, sob diferentes condições de vento.

\begin{tabular}{ccccccccc}
\hline Pressão & Vazão & Vento & Direção & \multicolumn{4}{c}{ Área molhada $\left(\mathbf{m}^{2}\right)$} \\
\cline { 5 - 9 } & $\mathbf{k P a}$ & $\mathbf{m} / \mathbf{s}$ & P.cardeal & 900 & $\mathbf{1 0 8 0}$ & $\mathbf{1 2 9 6}$ & $\mathbf{1 5 1 2}$ & $\mathbf{1 7 6 4}$ \\
\hline 300 & 4,96 & 0,03 & --- & 74,6 & 77,9 & 69,0 & 64,6 & 67,6 \\
300 & 4,98 & 1,03 & $\mathrm{~S}$ & 86,7 & 87,0 & 81,8 & 74,3 & 70,0 \\
350 & 5,29 & 0,47 & $\mathrm{SW}$ & 80,8 & 85,8 & 82,3 & 76,1 & 73,6 \\
350 & 5,26 & 0,19 & $\mathrm{~L}$ & 83,9 & 86,2 & 80,6 & 74,3 & 73,7 \\
400 & 5,80 & 2,25 & $\mathrm{SW}$ & 83,1 & 82,9 & 81,1 & 76,5 & 73,8 \\
400 & 5,80 & 1,00 & $\mathrm{~S}$ & 81,8 & 84,9 & 85,9 & 80,6 & 76,7 \\
400 & 5,80 & 0,05 & $\mathrm{~N}$ & 77,7 & 79,0 & 83,1 & 79,8 & 71,2 \\
450 & 6,03 & 1,44 & $\mathrm{NE}$ & 82,8 & 80,7 & 81,8 & 81,9 & 74,1 \\
450 & 6,01 & 0,11 & $\mathrm{~S}$ & 83,3 & 82,8 & 85,1 & 83,3 & 76,7 \\
500 & 6,56 & 0,06 & $\mathrm{~N}$ & 81,1 & 80,6 & 83,2 & 83,7 & 77,7 \\
500 & 6,61 & 0,17 & $\mathrm{~N}$ & 82,8 & 77,6 & 80,2 & 84,2 & 77,4 \\
\hline
\end{tabular}

Tabela 3: Valores de CUC para o aspersor ZN, com ângulo de trajetória de $24^{\circ}$, em função da pressão e da área molhada, sob diferentes condições de vento.

\begin{tabular}{cccccccccc}
\hline Pressão & Vazão & Vento & Direção & \multicolumn{6}{c}{ Área molhada $\left(\mathbf{m}^{2}\right)$} \\
\cline { 5 - 9 } & 1/s & m/s & P.cardeal & 900 & $\mathbf{1 0 8 0}$ & $\mathbf{1 2 9 6}$ & $\mathbf{1 5 1 2}$ & $\mathbf{1 7 6 4}$ \\
\hline 300 & 4,99 & 0,03 & N & 84,5 & 88,6 & 80,8 & 74,0 & 69,7 \\
300 & 5,03 & 0,75 & W & 84,9 & 86,6 & 82,8 & 75,4 & 72,2 \\
350 & 5,36 & 0,03 & -- & 79,2 & 82,6 & 84,2 & 78,2 & 72,9 \\
350 & 5,48 & 0,89 & SE & 87,1 & 84,6 & 81,7 & 78,2 & 72,7 \\
400 & 5,80 & 0,08 & SE & 85,6 & 87,1 & 89,1 & 83,8 & 79,5 \\
400 & 5,83 & 2,75 & SE & 86,7 & 80,0 & 71,9 & 64,1 & 54,1 \\
400 & 5,83 & 0,36 & NW & 84,0 & 83,5 & 87,4 & 84,5 & 77,2 \\
450 & 6,06 & 0,78 & L & 82,2 & 82,5 & 81,8 & 76,9 & 75,0 \\
450 & 6,03 & 0,22 & SW & 84,3 & 83,2 & 85,7 & 83,8 & 78,0 \\
500 & 6,49 & 1,25 & SE & 86,9 & 85,5 & 84,5 & 80,3 & 77,7 \\
500 & 6,49 & 0,00 & $\ldots--$ & 82,5 & 82,3 & 85,5 & 84,1 & 77,6 \\
500 & 6,49 & 0,69 & NW & 84,9 & 85,3 & 89,0 & 86,0 & 80,0 \\
\hline
\end{tabular}


Tabela 4: Valores de CUC para o aspersor $Z N$, com ângulo de trajetória de $27^{\circ}$, em função da pressão e da área molhada, sob diferentes condições de vento.

\begin{tabular}{|c|c|c|c|c|c|c|c|c|}
\hline \multirow{2}{*}{$\begin{array}{c}\text { Pressão } \\
\text { kPa }\end{array}$} & \multirow{2}{*}{$\begin{array}{c}\text { Vazão } \\
\text { l/s }\end{array}$} & \multirow{2}{*}{$\begin{array}{c}\text { Vento } \\
\mathrm{m} / \mathrm{s}\end{array}$} & \multirow{2}{*}{$\begin{array}{c}\text { Direção } \\
\text { P.cardeal }\end{array}$} & \multicolumn{5}{|c|}{ Área molhada $\left(\mathrm{m}^{2}\right)$} \\
\hline & & & & 900 & 1080 & 1296 & 1512 & 1764 \\
\hline 300 & 4,96 & 0,75 & SE & 82,9 & 83,6 & 79,6 & 73,6 & 72,1 \\
\hline 300 & 4,96 & 1,47 & SE & 84,4 & 80,6 & 76,2 & 63,8 & 56,6 \\
\hline 300 & 4,96 & 0,00 & -.. & 82,8 & 85,3 & 83,5 & 76,0 & 71,7 \\
\hline 350 & 5,40 & 0,06 & NW & 78,5 & 80,9 & 78,0 & 73,4 & 70,8 \\
\hline 350 & 5,34 & 1,03 & s & 91,2 & 91,7 & 87,4 & 80,5 & 78,0 \\
\hline 400 & 5,88 & 1,50 & $\mathrm{~N}$ & 83,2 & 86,2 & 82,5 & 76,7 & 73,8 \\
\hline 400 & 5,88 & 0,72 & SE & 87,4 & 88,9 & 89,8 & 86,3 & 83,5 \\
\hline 400 & 5,88 & 1,78 & S & 84,7 & 82,7 & 81,5 & 72,8 & 63,7 \\
\hline 450 & 6,07 & 0,53 & NE & 83,7 & 84,0 & 83,8 & 78,1 & 71,0 \\
\hline 450 & 6,01 & 1,58 & SW & 87,2 & 87,8 & 84,8 & 76,1 & 73,1 \\
\hline 500 & 6,62 & 0,94 & NE & 81,1 & 82,3 & 82,9 & 83,0 & 77,4 \\
\hline 500 & 6,62 & 2,08 & $\mathrm{NE}$ & 83,9 & 82,3 & 78,3 & 75,3 & 73,0 \\
\hline 500 & 6,87 & 0,42 & NE & 81,8 & 81,0 & 81,6 & 77,9 & 72,8 \\
\hline
\end{tabular}

Tabela 5: Valores de CUC para o aspersor ZN, com ângulo de trajetória de $30^{\circ}$, em função da pressão e da área molhada, sob diferentes condições de vento.

\begin{tabular}{|c|c|c|c|c|c|c|c|c|}
\hline \multirow{3}{*}{$\begin{array}{c}\text { Pressão } \\
\text { kPa } \\
300\end{array}$} & \multirow{2}{*}{$\begin{array}{c}\text { Vazão } \\
\text { l/s }\end{array}$} & \multirow{2}{*}{$\begin{array}{c}\text { Vento } \\
\mathrm{m} / \mathrm{s}\end{array}$} & \multirow{2}{*}{$\begin{array}{c}\text { Direção } \\
\text { P.cardeal }\end{array}$} & \multicolumn{5}{|c|}{ Area molhada $\left(\mathbf{m}^{2}\right)$} \\
\hline & & & & 900 & 1080 & 1296 & 1512 & 1764 \\
\hline & 4,99 & 0,35 & $\mathrm{~N}$ & 79,9 & 82,6 & 76,3 & 75,2 & 75,9 \\
\hline 300 & 4,99 & 0,35 & $\mathrm{~N}$ & 86,1 & 84,4 & 79,8 & 77,7 & 76,9 \\
\hline 350 & 5,29 & 0,86 & NE & 84,7 & 81,3 & 78,7 & 73,7 & 73,6 \\
\hline 350 & 5,29 & 1,18 & NW & 82,1 & 83,2 & 83,7 & 80,2 & 76,6 \\
\hline 400 & 5,80 & 0,47 & SW & 81,6 & 82,9 & 82,0 & 80,0 & 74,0 \\
\hline 400 & 5,80 & 0,86 & $\mathrm{~N}$ & 83,5 & 83,9 & 83,0 & 79,5 & 76,9 \\
\hline 450 & 6,10 & 0,48 & SW & 80,0 & 81,2 & 80,4 & 81,5 & 77,5 \\
\hline 450 & 6,10 & 0,50 & $w$ & 77,7 & 77,9 & 77,5 & 80,4 & 75,4 \\
\hline 500 & 6,58 & 0,62 & SE & 84,6 & 84,0 & 84,0 & 82,8 & 80,0 \\
\hline 500 & 6,58 & 0,96 & $L$ & 85,7 & 83,0 & 80,5 & 79,4 & 75,9 \\
\hline
\end{tabular}


Tomando-se valores de coeficientes de uniformidade de Christiansen (CUC) maiores ou iguais a $80 \%$, conforme descritos em OLITTA (1978), CHRISTIANSEN (1942), DAVIS (1966) e DAKER (1976) e analisandose mais apuradamente os resultados mostrados nas tabelas de 1 a 5 , algumas observações podem ser feitas.

Pela Tabela 1 (ângulo de $18^{\circ}$ ), pode ser observado que maiores pressões de operação proporcionaram maiores áreas molhadas. Pressões acima de $450 \mathrm{kPa}$ proporcionaram áreas até $1512 \mathrm{~m}^{2}$. Para pressões de $300 \mathrm{kPa}$, a área molhada chegou a $1080 \mathrm{~m}^{2}$ e, para pressões de 350 e 400 $\mathrm{kPa}$, as áreas molhadas foram consideradas até $1296 \mathrm{~m}^{2}$. Esses menores valores de área podem ser função do pequeno ângulo de trajetória do jato. As velocidades médias do vento referentes a esses ensaios encontram-se dentro dos valores adotados pela norma da ABNT para ensaios de aspersores, ou seja, abaixo de $2,0 \mathrm{~m} / \mathrm{s}$.

Com relação à uniformidade de distribuição, pode ser observado que, para cada uma das pressões estudadas, numa dada área molhada, ocorreu melhora nos valores de CUC à medida que as velocidades médias do vento se distanciavam de zero. Nessas condições, o vento auxiliou na redistribuição da água sobre a área de ensaio. Essas observações entram em desacordo com a s observações de GOMIDE (1978), ARRUDA (1981) e PAZ (1990), segundo as quais as áreas sofrem um decréscimo significativo à medida que crescem as velocidades médias do vento, para qualquer pressão de operação.

Para o aspersor canhão estudado, em baixos valores de ângulo de trajetória, a velocidade do vento afetou a uniformidade de distribuição de água, contradizendo WITHERS \& WIPOND (1977), os quais observaram que a uniformidade de distribuição de água é pouco afetada por ventos de zero a $2,2 \mathrm{~m} / \mathrm{s}$.

Em relação ao ângulo de $21^{\circ}$ (Tabela 2), pode ser observada uma melhora nos valores de área molhada à medida que se aumentou a pressão de operação. Nas pressões de 300 e $350 \mathrm{kPa}$, as maiores 
áreas molhadas obtidas foram de $1296 \mathrm{~m}^{2}$. Para pressões acima desses valores, de maneira geral, as áreas molhadas aumentaram para $1512 \mathrm{~m}^{2}$.

A velocidade média do vento teve pouca influência entre os ensaios, em relação à área molhada para uma mesma pressão. Apenas as pressões acima de $400 \mathrm{kPa}$, proporcionaram maiores espaçamentos.

No caso do ângulo de $24^{\circ}$ (Tabela 3), pressões de 300 e $350 \mathrm{kPa}$ proporcionaram áreas molhadas até $1296 \mathrm{~m}^{2}$. Para pressões acima de $400 \mathrm{kPa}$, essa área chegou a $1512 \mathrm{~m}^{2}$.

A variação da velocidade média do vento entre 0 e $2,75 \mathrm{~m} / \mathrm{s}$ não mostrou grandes diferenças em termos de CUCs obtidos, na faixa de pressão utilizada nos testes. Fixando-se uma determinada pressão, pode ser observada alguma semelhança em termos de áreas molhadas proporcionadas, independentemente das velocidade médias de vento dos ensaios. Para a pressão de $400 \mathrm{kPa}$, nota-se que, para uma velocidade média do vento acima dos padrões admitidos pela ABNT (menor que $2,0 \mathrm{~m} / \mathrm{s}$ ), os valores de CUC se reduziram, mas, mesmo assim, encontraram-se acima de $80 \%$ para áreas molhadas menores $\left(900\right.$ e $1080 \mathrm{~m}^{2}$ ).

No caso do ângulo de $27^{\circ}$ (Tabela 4), produziu-se praticamente uma única faixa de área molhada $\left(1296 \mathrm{~m}^{2}\right)$, proporcionada pelas pressões de 300 a $500 \mathrm{kPa}$. Apenas um ensaio, com pressão de $400 \mathrm{kPa}$, proporcionou área molhada de $1764 \mathrm{~m}^{2}$, quando a velocidade média do vento apresentou valor de $0,72 \mathrm{~m} / \mathrm{s}$.

A velocidade média de vento com valores próximos a $1,00 \mathrm{~m} / \mathrm{s}$ proporcionou melhores valores para o CUC. Com velocidades de vento mais elevadas $(1,47 \mathrm{~m} / \mathrm{s})$, os valores de CUC foram melhores apenas em áreas equivalentes a $900 \mathrm{~m}^{2}$, e reduziram-se à medida que essa área foi aumentada.

Para pressões de $350 \mathrm{kPa}$, os valores de velocidade média de vento próximos a $1,00 \mathrm{~m} / \mathrm{s}$ produziram melhores resultados de CUC. O mesmo ocorreu com pressões acima de $400 \mathrm{kPa}$. Os maiores valores de velocidade média de vento $(1,50$ e 1,78m/s) implicaram bons valores de CUC 
até a área molhada de $1296 \mathrm{~m}^{2}$, reduzindo-se, em seguida, a valores abaixo de $80 \%$. Para pressões de 450 e $500 \mathrm{kPa}$, a tendência foi praticamente a mesma: valores de vento próximos a $1,00 \mathrm{~m} / \mathrm{s}$ corresponderam a melhores valores de CUC, para áreas molhadas de $1296 \mathrm{~m}^{2}$. Apenas na pressão de $500 \mathrm{kPa}$, essa área foi ampliada para $1512 \mathrm{~m}^{2}$, com vento de $0,94 \mathrm{~m} / \mathrm{s}$. Valores de vento médio acima de $2,0 \mathrm{~m} / \mathrm{s}$ acarretaram redução nos valores de CUC, sendo que o mesmo se apresentou acima de $80 \%$ somente nas pequenas áreas molhadas.

$\mathrm{O}$ ângulo de $30^{\circ}$ (Tabela 5) proporcionou área molhada de $1512 \mathrm{~m}^{2}$, para pressões acima de $400 \mathrm{kPa}$.

Dentro de uma mesma faixa de pressão, os valores de CUC foram semelhantes para as velocidades médias de vento medidas. Houve uma tendência a melhores valores de CUC para velocidades menores de vento, à medida que aumentou a pressão de operação do aspersor. Isso pode ser explicado pela maior deriva do jato de água, pelo vento, à maiores pressões (gotas menores), principalmente à medida que se aumentaram as áreas molhadas.

Analisando-se mais generalizadamente os efeitos da pressão de operação em relação à área molhada e considerando-se a faixa de velocidades médias do vento nos ensaios de distribuição de água para CUC $\geq 80 \%$, pode ser observado, pelas Tabelas de 1 a 5 , que os ângulos de $18^{\circ}$ e $21^{\circ}$ proporcionaram maiores áreas molhadas em cada uma das pressões de operação. No caso do ângulo de $24^{\circ}$, essas áreas podem ser ampliadas para $1296 \mathrm{~m}^{2}$, nas pressões de $300 \mathrm{kPa}$, e $1512 \mathrm{~m}^{2}$, nas pressões de $400 \mathrm{kPa}$.

Houve, dessa maneira, um pequeno acréscimo em termos de área molhada para o ângulo de $24^{\circ}$. Esse ângulo foi o que apresentou melhor desempenho, em termos da combinação área molhada "versus" pressão, nas condições de velocidade média de vento estudadas.

Pode ser também observado, pelas Tabelas de 1 a 5 , que há uma tendência de os testes realizados com valores de vento próximos a zero, numa mesma condição de pressão, apresentarem valores de CUC inferiores aos testes com ventos diferentes de zero, principalmente numa faixa 
de 0,5 a $1,0 \mathrm{~m} / \mathrm{s}$. Isso pode ser aceito, uma vez que são valores médios de vento ocorridos durante a realização dos testes e que esse vento pode estar favorecendo a redistribuição mais uniforme da água sobre os coletores, já que são valores abaixo dos $2,0 \mathrm{~m} / \mathrm{s}$ de vento médio, admitidos por norma. Esses resultados, considerando-se a média dos ensaios, apresentam-se em concordância com o que foi observado por WITHERS \& WIPOND (1977), segundo os quais a velocidade média de vento entre 0,0 e 2,2m/s não afetou os valores de uniformidade, assim como a velocidade média de vento até $3,61 \mathrm{~m} / \mathrm{s}$ não chegou a prejudicar essa uniformidade.

Outra observação feita é que, nas condições do estudo (ângulo, pressão, área molhada e velocidade média de vento), em raríssimos casos, a área molhada de $1764 \mathrm{~m}^{2}(42 \times 42 \mathrm{~m})$ apresentou valores de CUC acima ou iguais a $80 \%$, o que pode indicar não ser essa uma boa combinação de espaçamento, quando se têm condições semelhantes às do estudo.

Se fosse considerada a variação de pressão de 300 a 500 $\mathrm{kPa}$, e analisada a variação dos valores de CUC em função de cada uma das áreas molhadas estudadas, poderiam ser observadas variações desde $7,8 \%$, para ângulo de trajetória de $18^{\circ}$ e área molhada de $1080 \mathrm{~m}^{2}$ até $47,9 \%$, para ângulo de trajetória de $24^{\circ}$ e área molhada de $1764 \mathrm{~m}^{2}$. Considerando-se a variação nos valores de CUC entre os ângulos de trajetória, para uma mesma área molhada, haveria maiores variações nas maiores áreas molhadas $\left(1764 \mathrm{~m}^{2}\right)$ e menores variações para áreas molhadas de 900 e $1080 \mathrm{~m}^{2}$.

\subsection{Modelo de regressão linear para a uniformidade}

A equação de ajuste, obtida a partir do modelo polinomial quadrático, para o coeficientes de uniformidade de Christiansen (CUC), em função do ângulo de trajetória $(A)$, da pressão de operação $(P)$, da área molhada $(E)$ e da velocidade média de vento $(V)$, para todos os testes de campo, é representada pela seguinte expressão: 


$$
\text { CUC }=12,4496+3,02514^{\star}(A)+0,13216^{\star}(P)+0,006108^{\star}(E)+
$$

$18,78856^{\star} V-0,0481478^{\star}\left(A^{2}\right)-0,0001543^{\star}\left(P^{2}\right)-0,0000138^{\star}\left(E^{2}\right)-2,3041863^{\star}\left(V^{2}\right)-$ $0,0019858^{\star}\left(A^{\star} P\right)+0,00023356^{\star}\left(A^{\star} E\right)-0,2358562^{\star}\left(A^{\star} V\right)+0,00004565^{\star}\left(P^{\star} E\right)-$ $0,0027476^{\star}\left(P^{\star} V\right)-0,0062759^{\star}(E \star V)$ em que
A: ângulo de saída do jato dos aspersores, em graus;
$P$ : pressão de operação dos aspersores, em kPa;
$E$ : espaçamento entre aspersores e entre linhas laterais, em $\mathrm{m}^{2}$;
$\mathrm{V}$ : velocidade média do vento, em $\mathrm{m} / \mathrm{s}$;

Derivando-se a eq. (9) em função de ângulo, pressão, espaçamento e vento, e resolvendo-se o sistema de 4 (quatro) equações e 4 (quatro) incógnitas, obtem-se os valores ótimos de ângulo, pressão, espaçamento e vento, respectivamente de $19,8^{\circ} ; 367,7 \mathrm{kPa} ; 508,5 \mathrm{~m}^{2}$ $(22,55 \times 22,55 \mathrm{~m})$ e $2,15 \mathrm{~m} / \mathrm{s}$. O espaçamento comercial mais próximo seria $24 \times 24 m$.

O valor ótimo do coeficiente de uniformidade de Christiansen, obtido a partir dessa equação é de $87,8 \%$. Os parâmetros ângulo, pressão e espaçamento, que otimizam a eq. (9), demonstraram valores dentro da faixa considerada nos ensaios, com exceção do espaçamento. $O$ coeficiente de uniformidade Christiansen de $87,87 \%$ está acima do limite mínimo de 80\%, citado por CHRISTIANSEN (1942), DAVIS (1966), OLITTA (1978) e DAKER (1976). Esse valor relativamente elevado do CUC é função do pequeno espaçamento obtido, mesmo sob condições de vento médio acima dos $2 \mathrm{~m} / \mathrm{s}$ permitidos em ensaios de distribuição de água. $\mathrm{O}$ vento, nesse caso, ajudou a melhorar a distribuição da água nos coletores.

Considerando, que para a derivada segunda da eq. (9), em relação a ângulo de trajetória, pressão de operação, área molhada e velocidade média do vento, foram obtidos valores negativos respectivamente de $-0,096,-0,0003,-0,00003$ e $-4,608$, que se podem considerar pontos de máximo. Dessa maneira, os valores de ângulo de trajetória $\left(19,8^{\circ}\right)$, pressão de operação $(367,7 \mathrm{kPa})$, área molhada $\left(508,5 \mathrm{~m}^{2}\right)$, velocidade média do vento 
$(2,15 \mathrm{~m} / \mathrm{s})$ e CUC $(87,8 \%)$, representam pontos que maximizam o coeficiente de uniformidade de Christiansen, pela equação de regressão polinomial quadrática considerada.

\subsubsection{Testes estatísticos.}

4.2.1.1 Teste de significância dos parâmetros do modelo polinomial ajustado.

A Tabela 6, apresentada a seguir, resume 0 teste estatístico para o modelo ajustado (eq. 9), obtido através do programa QPro versão, 4.0, onde são considerados o teste $F$, o nível mínimo de significância e o coeficiente de determinação $\left(R^{2}\right)$ dos parâmetros da equação do CUC.

Tabela 6: Valores de $F$, nível mínimo de significância (NMS) e coeficiente de determinação $\left(R^{2}\right)$ para o modelo ajustado do CUC.

\begin{tabular}{ccccc}
\hline $\begin{array}{c}\text { Causas de } \\
\text { variação }\end{array}$ & $\begin{array}{c}\text { Graus de } \\
\text { liberdade -G.L. }\end{array}$ & $\mathbf{F}$ & N.M.S. & $\mathbf{R}^{2}$ \\
\hline Linear & 4 & 80,43 & 0,00 & 0,43 \\
Quadrática & 4 & 19,67 & 0,00 & 0,11 \\
Interações & 6 & 11,38 & 0,00 & 0,09 \\
\hline Total da & & & & \\
regressão & 14 & 32,72 & 0,00 & 0,63 \\
\hline Ángulo & 5 & 5,61 & 0,00 & \\
Pressão & 5 & 14,67 & 0,00 & \\
Area molhada & 5 & 72,12 & 0,00 & \\
Veloc. vento & 5 & 14,99 & 0,00 & \\
\hline
\end{tabular}

N.M.S. Nivel mínimo de significância

$R^{2}$ : coeficiente de determinação

Pode ser observado, pela Tabela 6 , que, no modelo ajustado do CUC, os componentes lineares, quadráticos e as interações lineares apresentam significância em nivel de $1 \%$ de probabilidade, indicando 
haver relação funcional entre os parâmetros de projeto estudados (ângulo de trajetória do jato, pressão de operação, área molhada e velocidade média do vento). Analisando-se os valores de $\mathrm{F}$, obtidos para cada um dos parâmetros do projeto individualmente (5,61 para ângulo, 14,67 para pressão, 72,12 para área molhada e 14,99 para velocidade média de vento), e comparando-se com o valor tabelado de 3,02 , para 5 graus de liberdade dos tratamentos e 265 graus de liberdade para os residuos, é possível observar-se que os quatro influem significativamente, em nível de $1 \%$ de probabilidade, no comportamento do CUC.

Dessa maneira, pode-se dizer que, em termos de projeto para um sistema nas configurações apresentadas, a uniformidade de distribuição de água, representada pelo CUC, depende dos parâmetros ângulo de trajetória do jato de água, pressão de operação, área molhada em função do espaçamento entre aspersores e entre linhas laterais e velocidade média do vento.

Os resultados dos testes de significância para cada um dos parâmetros da equação de regressão, obtidos através das análises efetuadas pelo teste $T$, são apresentados na Tabela 7 .

Analisando-se a Tabela 7, pode-se perceber que 0 valor do coeficiente de determinação $\left(R^{2}\right)$ igual a 0,63 é relativamente baixo, mas deve-se considerar o elevado número de dados envolvidos na análise. Assim sendo, mesmo com esse baixo valor de $R^{2}$, o ajuste pode ser considerado satisfatório.

Pode-se verificar também, pela Tabela 7 , que, no modelo polinomial quadrático ajustado do CUC (eq. 9), os coeficientes estimados dos parâmetros de projeto, quando analisados pelos valores apresentados do teste $T$ e comparados pelos valores tabelados de $T$, mostram que os componentes lineares $A(3,969), P(2,99)$ e $V(5,321)$; os componentes quadráticos $A^{2}$ $(3,394), P^{2}(3,169), E^{2}(5,326)$ e $V^{2}(5,388)$; e os componentes das interações lineares AP $(2,609), \operatorname{PE}(4,861)$ e EV $(5,858)$ foram significativos em nível de 
$1 \%$ de probabilidade, pois são maiores que o valor 2,58 , para 265 graus de liberdade. Nesse caso, tais coeficientes influem na resposta da variável CUC.

Tabela 7: Coeficientes estimados dos parâmetros da equação de regressão ajustada, valores e nível mínimo de significância do teste $T$, para 280 observações e 265 graus de liberdade.

\begin{tabular}{ccccc}
\hline Parâmetro & Coeficiente & $\begin{array}{c}\text { Erro padrão do } \\
\text { coeficiente }\end{array}$ & Test T & $\begin{array}{c}\text { Nivel de } \\
\text { (significância) }\end{array}$ \\
\hline Constante & 12,4496 & 2,033 & 6,123 & 0,000 \\
A & 3,02514 & 0,762 & 3,969 & 0,000 \\
P & 0,13216 & 0,044 & 2,999 & 0,003 \\
E & 0,00611 & 0,009 & 0,697 & 0,487 \\
V & 18,78856 & 3,531 & 5,321 & 0,000 \\
$A^{2}$ & $-0,04815$ & 0,014 & $-3,394$ & 0,000 \\
$P^{2}$ & $-0,00015$ & 0,000 & $-3,169$ & 0,002 \\
$E^{2}$ & $-0,00001$ & 0,000 & $-5,326$ & 0,000 \\
$V^{2}$ & $-2,30419$ & 0,428 & $-5,388$ & 0,000 \\
$A P$ & $-0,00199$ & 0,001 & $-2,609$ & 0,010 \\
AE & 0,00023 & 0,000 & 1,411 & 0,159 \\
AV & $-0,23586$ & 0,106 & $-2,234$ & 0,027 \\
$P E$ & 0,000046 & 0,000 & 4,861 & 0,000 \\
PV & $-0,00275$ & 0,006 & $-0,454$ & 0,650 \\
EV & $-0,00628$ & 0,001 & $-5,858$ & 0,000 \\
\hline$R^{2}=0,633$ & & & &
\end{tabular}

A influência do coeficiente da interação linear $\operatorname{AV}(2,234)$ tem significância em nivel de $5 \%$ de probabilidade, pelo teseT, considerandose 265 graus de liberdade.

Observando a Tabela 7, pode-se notar que a componente linear $E(0,697)$, bem como as componentes das interações lineares $A E$ $(1,411)$ e PV $(0,454)$, não são significativas nem em nivel de $10 \%$ de probabilidade, pois apresentam valores menores que o tabelado de 1,65, não influenciando nos resultados do CUC. Dessa maneira, a grosso modo, não 
poderiam ser descartados da equação, sem que os resultados fossem alterados.

Pode-se dizer que mesmo com alguns componentes da equação apresentando coeficientes não significativos, isto é, não tendo influência na resposta do CUC, há indícios de existência de relação funcional (linear, quadrática e das interações) entre os parâmetros de projeto estudados (combinações de ângulo, pressão, área molhada e velocidade média do vento) e os valores dos coeficientes de uniformidade de Christiansen (CUC).

\subsubsection{Teste do grau de adequação do CUC.}

A Figura 1 ilustra os valores de CUC, previstos pela equação de regressão, comparados com os valores de CUC observados nos ensaios de distribuição de água, calculados pelo programa CATH3D.

Pode ser observado, pela Figura (1), que existe uma tendência de ajuste entre os valores de CUC, previstos pelo modelo e os valores de CUC observados, utilizando-se o programa CATCH3D. Pequenas discrepâncias podem ser observadas para baixos valores de CUC (até $70 \%$, aproximadamente), onde o modelo superestima os resultados. A partir desse valor, o ajuste se torna muito bom. Pelo teste do grau de adequação (d), descrito em WILLMOTT (1982) e obtido pela eq. (10), o valor de 0,8759 está indicando haver bom grau de estimativa da variável CUC pela equação de regressão. Isso vem reforçar a idéia de se utilizar a equação de regressão dos dados, obtida pelo ajuste, para a estimativa da uniformdiade (CUC). 


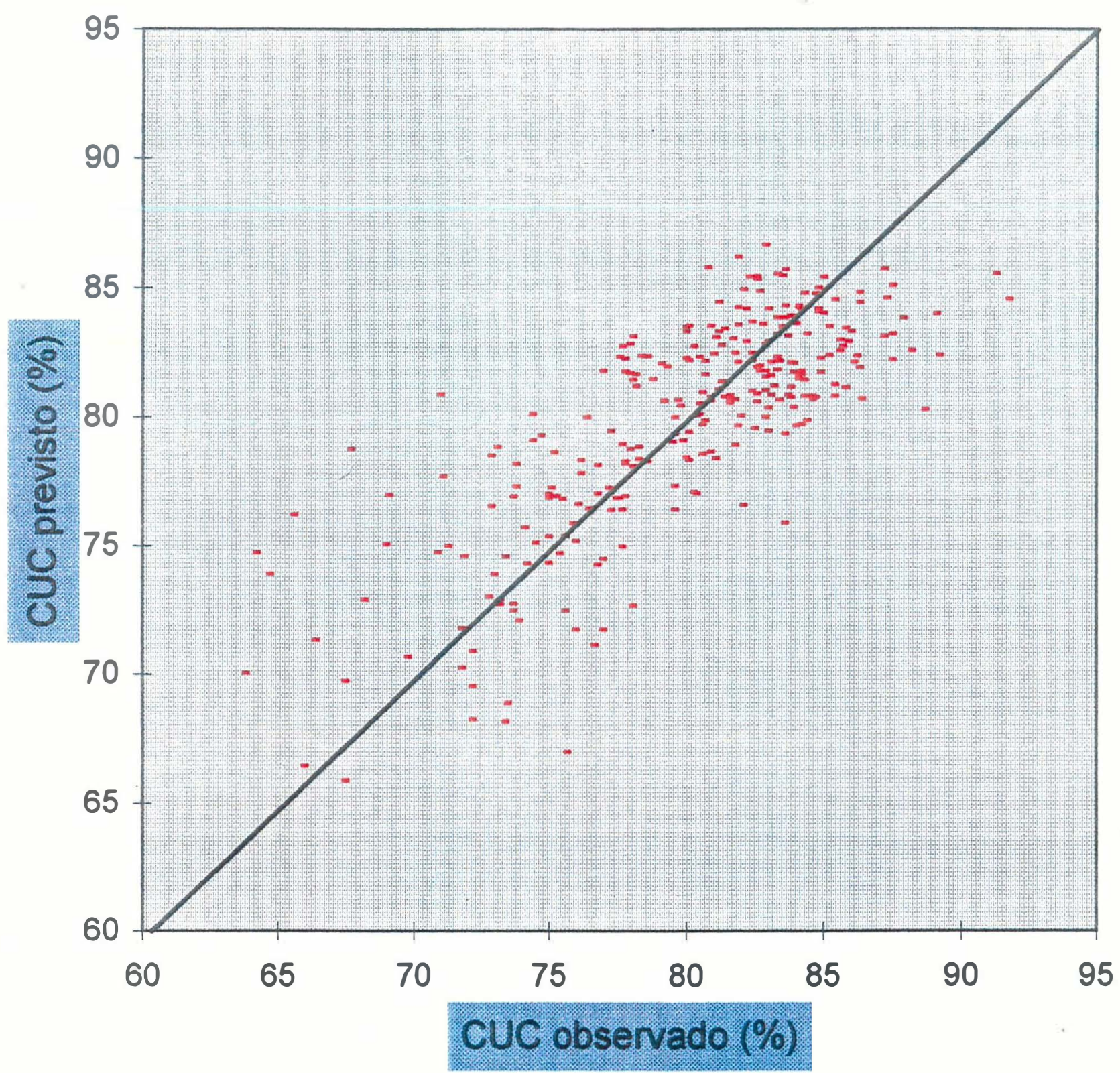

Figura 1: Representação gráfica dos valores de CUC (\%) previstos pelo modelo de regressão polinomial quadrático ajustado, e dos valores de CUC (\%) observados (obtidos com os dados de campo). 


\subsubsection{Aplicação do modelo ajustado}

De acordo com o modelo ajustado no item 3.4.1.1, são apresentados, nas tabelas 8 a 12, os limites inferior e superior de velocidade média de vento que mantêm os coeficientes de uniformidade de Christiansen acima ou, no máximo, iguais a $80 \%$, obtidos através da utilização das expressões representadas pela eq. (9). São também apresentados os valores de CUC (\%) máximos, bem como os valores de velocidades médias de vento $(\mathrm{m} / \mathrm{s})$ necessários para manter esse máximos valores de CUC, obtidos pela derivação das expressões equivalentes à eq. (9), igualando-se as mesmas a zero.

Tabela 08: Limites inferior e superior de velocidade média de vento, para CUC $\geq 80 \%$, e velocidade média de vento para CUC máximo, em função de pressão e área molhada, em ângulo de trajetória de $18^{\circ}$.

\begin{tabular}{cccccc}
\hline Ángulo & Pressáo & Área molhada & $\begin{array}{c}\text { Vento para CUC } \geq \\
\mathbf{8 0 \%}\end{array}$ & $\begin{array}{c}\text { Vento para CUC } \\
\text { máx. }\end{array}$ & CUC mảximo \\
(graus) & $\mathbf{( k P a )}$ & $(\mathbf{m} / \mathbf{s})$ & $(\mathbf{m} / \mathbf{s})$ & $(\%)$ \\
\hline 18 & 300 & 900 & $0,46-3,04$ & 1,75 & 83,8 \\
18 & 300 & 1080 & $0,73-2,28$ & 1,51 & 81,4 \\
18 & 350 & 900 & $0,18-3,26$ & 1,72 & 85,5 \\
18 & 350 & 1080 & $0,25-2,70$ & 1,48 & 83,5 \\
18 & 350 & 1296 & $0,85-1,52$ & 1,18 & 80,3 \\
18 & 400 & 900 & $0,043,35$ & 1,09 & 86,3 \\
18 & 400 & 1080 & $0,01-2,88$ & 1,45 & 84,8 \\
18 & 400 & 1296 & $0,20-2,10$ & 1,15 & 82,1 \\
18 & 450 & 900 & $0,00-3,33$ & 1,66 & 86,4 \\
18 & 450 & 1080 & $0,00-2,93$ & 1,42 & 85,3 \\
18 & 450 & 1296 & $0,00-2,29$ & 1,12 & 83,2 \\
18 & 400 & 1512 & $0,60-1,06$ & 0,83 & 80,1 \\
18 & 500 & 900 & $0,06-3,21$ & 1,83 & 85,7 \\
18 & 500 & 1080 & $0,00-2,87$ & 1,39 & 85,1 \\
18 & 500 & 1296 & $0,00-2,32$ & 1,09 & 83,5 \\
18 & 500 & 1512 & $0,15-1,44$ & 0,80 & 80,9 \\
\hline
\end{tabular}


Tabela 09: Limites inferior e superior de velocidade média de vento, para $C U C \geq 80 \%$, e velocidade média de vento para CUC máximo, em função de pressão e área molhada, para ângulo de trajetória de $21^{\circ}$.

\begin{tabular}{|c|c|c|c|c|c|}
\hline Ángulo & $\begin{array}{l}\text { Pressāo } \\
\text { (KPa) }\end{array}$ & $\begin{array}{c}\text { Área molhada } \\
\left(\mathrm{m}^{2}\right)\end{array}$ & $\begin{array}{c}\text { Vento para CUC } \geq \\
80 \% \\
(\mathrm{~m} / \mathrm{s})\end{array}$ & $\begin{array}{l}\text { Vento para CUC } \\
\text { máx. } \\
(\mathrm{m} / \mathrm{s})\end{array}$ & CUC máximo \\
\hline 21 & 300 & 900 & $0,13-3,06$ & 1,60 & 84,9 \\
\hline 21 & 300 & 1080 & $0,25-2,45$ & 1,35 & 82,8 \\
\hline 21 & 350 & 900 & $0,08-3,22$ & 1,57 & 86,3 \\
\hline 21 & 350 & 1080 & $0, \infty-2,73$ & 1,32 & 84,6 \\
\hline 21 & 350 & 1296 & $0,16-1,90$ & 1,03 & 81,7 \\
\hline 21 & 400 & 900 & $0, \infty 0-3,26$ & 1,54 & 86,9 \\
\hline 21 & 400 & 1080 & $0, \infty-2,85$ & 1,29 & 85,6 \\
\hline 21 & 400 & 1296 & $0,00-2,19$ & 1,00 & 83,3 \\
\hline 21 & 400 & 1512 & $0,51-0,90$ & 0,70 & 80,1 \\
\hline 21 & 450 & 900 & $0,19-3,21$ & 1,51 & 86,7 \\
\hline 21 & 450 & 1080 & $0, \infty 0-2,86$ & 1,26 & 85,9 \\
\hline 21 & 450 & 1296 & $0,00-2,30$ & 0,97 & 84,1 \\
\hline 21 & 450 & 1512 & $0, \infty-1,46$ & 0,67 & 81,4 \\
\hline 21 & 500 & 900 & $0,00-3,05$ & 1,48 & 85,7 \\
\hline 21 & 500 & 1080 & $0, \infty-2,76$ & 1,23 & 83,4 \\
\hline 21 & 500 & 1296 & $0,40-2,27$ & 0,94 & 84,1 \\
\hline 21 & 500 & 1512 & $0,00-1,57$ & 0,65 & 82,0 \\
\hline
\end{tabular}

Tabela 10: Limites inferior e superior de velocidade média de vento, para $C U C \geq 80 \%$, e velocidade média de vento para CUC máximo, em funçåo de pressão e área molhada, para ângulo de trajetória de $24^{\circ}$.

\begin{tabular}{cccccc}
\hline Ángulo & Pressão & Area molhada & $\begin{array}{c}\text { Vento para CUC } \geq \\
\mathbf{8 0 \%}\end{array}$ & $\begin{array}{c}\text { Vento para CUC } \\
\text { máx. }\end{array}$ & CUC máximo \\
(graus) & $\mathbf{( k P a )}$ & $\left(\mathbf{m}^{2}\right)$ & $(\mathbf{m} / \mathbf{s})$ & $(\mathbf{m} / \mathbf{s})$ & $(\%)$ \\
\hline 24 & 300 & 900 & $0,00-2,96$ & 1,44 & 85,3 \\
24 & 300 & 1080 & $0,00-2,42$ & 1,20 & 83,4 \\
24 & 300 & 1296 & $0,48-1,33$ & 0,91 & 80,4 \\
24 & 350 & 900 & $0,00-3,07$ & 1,41 & 86,3 \\
24 & 350 & 1080 & $0,00-2,64$ & 1,17 & 85,0 \\
24 & 350 & 1296 & $0,00-1,91$ & 0,88 & 82,5 \\
24 & 400 & 900 & $0,00-3,08$ & 1,38 & 86,6 \\
24 & 400 & 1080 & $0,00-2,71$ & 1,14 & 85,7 \\
24 & 400 & 1296 & $0,00-2,12$ & 0,85 & 83,7 \\
24 & 400 & 1512 & $0,00-1,18$ & 0,55 & 80,9 \\
24 & 450 & 900 & $0,00-2,99$ & 1,35 & 86,2 \\
24 & 450 & 1080 & $0,00-2,08$ & 1,11 & 85,7 \\
24 & 450 & 1296 & $0,00-2,17$ & 0,82 & 84,3 \\
24 & 450 & 1512 & $0,00-1,44$ & 0,52 & 81,9 \\
24 & 500 & 900 & $0,00-2,79$ & 1,33 & 84,9 \\
24 & 500 & 1080 & $0,00-2,54$ & 1,08 & 84,9 \\
24 & 500 & 1296 & $0,00-2,10$ & 0,79 & 84,0 \\
24 & 500 & 1512 & $0,00-1,47$ & 0,49 & 82,2 \\
\hline
\end{tabular}


Tabela 11: Limites inferior e superior de velocidade média de vento, para CUC $\geq 80 \%$, e velocidade média de vento para CUC máximo, em funçăo de pressão e área molhada, para ângulo de trajetória de $27^{0}$.

\begin{tabular}{cccccc}
\hline Angulo & Pressão & Área molhada & $\begin{array}{c}\text { Vento para CUC } \geq \\
\mathbf{8 0} \%\end{array}$ & $\begin{array}{c}\text { Vento para CUC } \\
\text { máx. }\end{array}$ & CUC máximo \\
(graus) & $\mathbf{( k P a )}$ & $\left(\mathbf{m}^{2}\right)$ & $(\mathbf{m} / \mathbf{s})$ & $(\mathbf{m} / \mathbf{s})$ & $\mathbf{( \% )}$ \\
\hline 27 & 300 & 900 & $0,00-2,74$ & 1,29 & 84,9 \\
27 & 300 & 1080 & $0,00-2,25$ & 1,05 & 83,3 \\
27 & 300 & 1296 & $0,22-1,29$ & 0,75 & 80,7 \\
27 & 350 & 900 & $0,00-2,83$ & 1,26 & 85,7 \\
27 & 350 & 1080 & $0,00-2,42$ & 1,02 & 84,6 \\
27 & 350 & 1296 & $0,00-1,75$ & 0,72 & 82,4 \\
27 & 400 & 900 & $0,342,80$ & 1,23 & 85,7 \\
27 & 400 & 1080 & $0,00-2,46$ & 0,99 & 85,0 \\
27 & 400 & 1296 & $0,00-1,91$ & 0,69 & 83,4 \\
27 & 400 & 1512 & $0,00-1,04$ & 0,40 & 81,0 \\
27 & 450 & 900 & $0,00-2,66$ & 1,20 & 84,9 \\
27 & 450 & 1080 & $0,00-2,39$ & 0,96 & 84,7 \\
27 & 450 & 1296 & $0,00-1,92$ & 0,66 & 83,7 \\
27 & 450 & 1512 & $0,00-1,23$ & 0,37 & 81,7 \\
27 & 500 & 900 & $0,00-2,39$ & 1,17 & 83,4 \\
27 & 500 & 1080 & $0,00-2,19$ & 0,93 & 83,7 \\
27 & 500 & 1296 & $0,00-1,80$ & 0,63 & 83,1 \\
27 & 500 & 1512 & $0,00-1,20$ & 0,34 & 81,7 \\
\hline
\end{tabular}

Tabela 12: Limites inferior e superior de velocidade média de vento, para CUC $\geq 80 \%$, e velocidade média de vento para CUC máximo, em funçăo de pressăo e área molhada, para ângulo de trajetória de $30^{\circ}$.

\begin{tabular}{cccccc}
\hline Ángulo & Pressão & Área molhada & $\begin{array}{c}\text { Vento para CUC } \geq \\
80 \%\end{array}$ & $\begin{array}{c}\text { Vento para CUC } \\
\text { máx. }\end{array}$ & CUC máximo \\
(graus) & (kPa) & $\left(\mathbf{m}^{2}\right)$ & $(\mathbf{m} / \mathbf{s})$ & $(\mathbf{m} / \mathbf{s})$ & $(\%)$ \\
\hline 30 & 300 & 900 & $0,00-2,40$ & 1,14 & 83,7 \\
30 & 300 & 1080 & $0,00-1,92$ & 0,89 & 82,5 \\
30 & 300 & 1296 & $0,350,85$ & 0,60 & 80,1 \\
30 & 350 & 900 & $0,00-2,46$ & 1,11 & 84,2 \\
30 & 350 & 1080 & $0,00-2,08$ & 0,86 & 83,4 \\
30 & 350 & 1296 & $0,00-1,41$ & 0,57 & 81,6 \\
30 & 400 & 900 & $0,00-2,39$ & 1,08 & 84,0 \\
30 & 400 & 1080 & $0,00-2,08$ & 0,83 & 83,6 \\
30 & 400 & 1296 & $0,00-1,55$ & 0,54 & 82,4 \\
30 & 450 & 900 & $0,00-2,17$ & 1,05 & 82,9 \\
30 & 450 & 1080 & $0,00-1,95$ & 0,80 & 83,0 \\
30 & 450 & 1296 & $0,00-1,51$ & 0,51 & 82,3 \\
30 & 450 & 1512 & $0,00-0,78$ & 0,21 & 80,7 \\
30 & 500 & 900 & $0,32-1,72$ & 1,02 & 81,1 \\
30 & 500 & 1080 & $0,00-1, \varpi 3$ & 0,77 & 81,7 \\
30 & 500 & 1512 & $0,00-0, \varpi 3$ & 0,18 & 80,5 \\
30 & 500 & 1296 & $0,00-1,29$ & 0,48 & 81,5 \\
\hline
\end{tabular}


Pode ser observado, pela tabelas 8 a 12, que, mantendose a pressão de operação constante, para uma dado ângulo de trajetória, à medida que aumenta o espaçamento (área molhada), reduz-se a faixa de velocidade média de vento que admite $\mathrm{CUC} \geq 80 \%$ e, ao mesmo tempo, também se reduz a velocidade média do vento que dá o máximo valor de CUC. Reduzse, assim, o valor máximo do CUC nessas condições.

Por outro lado, mantendo-se o espaçamento (área molhada) constante, à medida que aumenta o valor da pressão de operação, reduz-se o valor da velocidade média do vento que corresponde ao CUC máximo.

De maneira geral, ’a medida que aumenta a pressão e mantém-se o espaçamento (área molhada), para um dado ângulo de trajetória, tem-se o valor de CUC pouco alterado. O ângulo de $24^{\circ}$ foi o que apresentou maior faixa de área molhada para cada pressão de operação, disponivel a ter CUC $\geq 80 \%$.

De posse do conhecimento dos dados de velocidade média de vento, numa dada região, e com os resultados apresentados nas tabelas 8 a 12, podem ser observadas duas situações diferentes.

\subsection{Avaliação do modelo para} dimensionamento de sistemas.

a) A velocidade média diária do vento é superior a $3,35 \mathrm{~m} / \mathrm{s}$. Nesses casos, de acordo com as condições do ensaio realizado, nenhuma das combinações (ângulo, pressão, área molhada) fornecerá coeficientes de uniformidade de Christiansen (CUC) maior que $80 \%$.

Se aceitarmos esse limite como máximo permissivel para se ter $C U C \geq 80 \%$, a irrigação por aspersão com aspersor canhão deve ser considerada inviável. Uma alternativa possível seria a realização dessa irrigação durante o período noturno, quando, de acordo com SMITH (1991), o 
valor da velocidade média do vento é cerca de $66 \%$ da aferida no período diurno.

Caso a velocidade média de vento à noite, assim calculada, forneça valores inferiores a $3,35 \mathrm{~m} / \mathrm{s}$ (conforme tabelas 8 a 12), o CUC deverá ser superior a $80 \%$. O passo seguinte é escolher qual valor da combinação (ângulo, pressão, área molhada) corresponde `a velocidade média de vento para CUC máximo, dadas as condições observadas.

b) Velocidade média do vento inferior a $3,35 \mathrm{~m} / \mathrm{s}$. Nesses casos, de maneira análoga à anterior, escolhe-se a combinação (ângulo, pressão, área molhada) correspondente à velocidade média do vento que resulta no máximo valor de CUC, nas condições da velocidade média do vento observado.

\subsection{Aplicação do modelo ajustado para} avaliação e redimensionamento de sistemas.

a) Existe a possibilidade apenas de mudança no espaçamento (área molhada). Para as condições de ângulo, pressão e área molhada da instalação, verificar se o valor da velocidade média do vento da região está dentro dos limites de vento determinados para se obter CUC $\geq 80 \%$.

b) A velocidade média do vento para a região está fora do intervalo permitido para as condições de ângulo, pressão e área molhada da instalação. Nesse caso, deve-se procurar qual o valor de área molhada para uma dada combinação (ângulo e pressão) que permita que a velocidade média do vento esteja dentro do intervalo de CUC $\geq 80 \%$.

c) A mudança do espaçamento (área molhada) não adequa o sistema para as condições de $C U C \geq 80 \%$. Nessa situação, deve-se verificar se, alterando a pressão de operação do sistema, é possivel encontrar valores de velocidade média de vento que se enquadrem dentro das condições de CUC $\geq 80 \%$. 


\section{CONCLUSÕES}

Para as condições do experimento realizado, pode-se inferir que:

1) O modelo de regressão polinomial quadrático ajustado estima adequadamente a uniformidade de distribuição;

2) A uniformidade de distribuição de água, medida pelo coeficiente de uniformidade de Christiansen (CUC), foi influenciada significativamente, em nivel de $1 \%$ de probabilidade pelos parâmetros ângulo, pressão de operação, espaçamento entre aspersores e entre linhas laterais, representados pela área molhada e velocidade média do vento, considerados no estudo;

3) O modelo polinomial quadrático ajustado para o CUC apresentou, na análise de regressão, um coeficiente de determinação $\left(r^{2}\right)$ de 0,633. Esse valor é adequado, em função da ampla gama de dados envolvidos na análise, e portanto, permite a recomendação desse modelo de ajuste, em condições semelhantes às observadas no estudo;

4) A configuração ótima para o sistema apresentou um ângulo de trajetória do jato de $19,8^{\circ}$, pressão de operação de $367,7 \mathrm{kPa}$, velocidade média do vento de $2,15 \mathrm{~m} / \mathrm{s}$ e uma área molhada de $508,5 \mathrm{~m}^{2}$, correspondendo a um espaçamento comercialmente disponível de $24 \times 24 \mathrm{~m}$. O valor ótimo do coeficiente de uniformidade de Christiansen (CUC) obtido foi de $87,9 \%$; 
5) Quanto maior o ângulo de saída do jato de água, menores são os valores de velocidade média de vento que permitem a obtenção de CUC $\geq 80 \%$, independentemente da pressão de serviço utilizada e do espaçamento considerado;

6) Para dimensionamento de projetos novos, o modelo ajustado para o CUC permite otimizar a instalação em termos de ângulo de trajetória, pressão de operação e espaçamento (área molhada), uma vez conhecida a condição de velocidade média de vento na região;

7) O modelo ajustado permite a avaliação e adequação de projetos já implantados, através da possibilidade de mudanças no espaçamento entre aspersores e/ou pressão de operação, uma vez conhecida a velocidade média do vento. 


\section{REFERÊNCIAS BIBILOGRÁFICAS}

ARRUDA, N. T. Análise de uniformidade da distribuição da água no sistema de irrigação por aspersão em linha. Viçosa, 1981. 80p. Dissertação (Mestrado-Universidade Federral de Viçosa).

ASSOCIAÇÃO BRASILEIRA DE NORMAS TÉCNICAS. Aspersores para irrigação. avaliação da distribuição de água: NBR 8989. São Paulo, 1985. $9 p$.

BARRETO, G. B. Irrigação: princípios, métodos e prática. Campinas: Instituto Campineiro de Ensino Agrícola, 1974. 1985p.

BERNARDO, S. Manual de irrigação. 5.ed. Viçosa: UFV., Imprensa Universitária, 1989 596p.

BERNUTH, R. D. von; GILLEY, J. R. Sprinkler droplet size distribution estimation from single leg test data. Transactions of the ASAE, v 27, n. 5 , p.1435-41, 1984.

BILANSKI, W. K; KIDDER, E. H. Factors that affect the distribution of water from a medium-pressure rotary irrigation sprinkler. Transactions of the ASAE, v.1, n.1, p.10-28, 1958.

BRANSCHEID, V. O; HART, W. E. Predicting field distribuitions of sprinkler systems. Transactions of the ASAE, v.11, n.6, p. 801-3, 808, 1968. 
CHRISTIANSEN, J. E. Irrigation by sprinkling. 2.ed. Berkeley: University of California, Experiment Station. 1942, 124p.(Bulletin, 670).

COELHO, R. D. Regulagens de aspersores e seus efeitos sobre a uniformidade de aplicação de água e produtividade das culturas. Piracicaba, 1990 141p. Dissertação (Metrado-Escola Superior de Agricultura "Luiz de Queiroz", Universidade de São Paulo).

COLOMBO, A.; MARTUCCI, G.; SCALOPPI, E. J. Espaçamento entre coletores em estudos de distribuição de água de aspersores. In: CONGRESSO BRASILEIRO DE ENGENHARIA AGRICOLA, 13. Rio de Janeiro, 1983. Anais. Rio de Janeiro:, SBEA, 1983. v.1, p.221-6.

CULVER, R; SINKER, R. F. Rapid assesment of sprinkler perfomance. Journal of Irrigation and Drainage Division, ASAE, v.92, n.1, p.1-17, 1986.

DADIAO, C. WALLENDER, W. W. Droplet size distribution and water application with low pressure sprinklers. Transactions of the ASAE, v.28, n.2, p.511-6, 1985.

DAKER, A. A água na agricultura: manual de hidráulica agrícola, irrigação e drenagem. 5.ed. Rio de Janeiro: Ed. Freitas Bastos, 1976. v.3,. 453p.

DAVIS, J. R. Measuring water distribution from sprinklers. Transactions of the ASAE, v.9, n.1, p. 94-7, 1966.

ESTADOS UNIDOS. Sprinkler irrigation. Department of Agricultural. Soil Conservation Service. Washington, 1983. cap.11, 121p. (National Engeneering Handbook. Irrigation, 15). 
FRIZZONE, J. A.. Irrigação por aspersão: uniformidade e eficiência. Piracicaba: ESALQ, Depto. Engenharia Rural, 1992. 53p. (Série Didática, 3).

FROST, K. P; SACHWALEN, H. C. Evapotranspiration during sprinkler irrigation. Transactions of the ASAE. v.3, n.1, p. 18-20,24.1960.

GOMIDE, R. L. Determinação e análise da uniformidade de distribuição da água no sistema de irrigação por aspersão. Viçosa, 1978, 87p. Dissertação (Mestrado-Universidade Federal de Viçosa).

HART, W. E. Overhead irrigation patterns parameters. Agricultural Engineering, v. 42, n.7, p. 354-355, July, 1961.

HART, W.E; HEERMANN, D.F. Evaluating water distribuitions of sprinkler irrigations systems. Fort Collins: Colorado State University, 1976. 42p. (Colorado Experimental Station Bulletin, 128).

HART, W. E; REYNOLDS, W. N. Analytical design of sprinkler systems. Transactions of the ASAE, v.9, n.1, p. 83-5, 89, Jan/Fev, 1965.

HEEMSTRA, I. H.; COLOMBO, A.; SCALOPPI, E. J. Influência do ângulo do jato na distribuição de água de aspersores rotativos. In: CONGRESSO BRASILEIRO DE ENGENHARIA AGRÍCOLA, 13. Rio de Janeiro, 1983. Anais. Rio de Janeiro: SBEA. 1983, v.1, p.213-9.

JAMES, L. G. Principles of farm irrigation systems design. New York: John Willey, 1988. 543p.

KELLER, J; BLIESNER, R. D. Sprinkler and trickle irrigation. New York: An Avi Book, 1990. 652p. 
KERR, G. L.; POCHOP, L. O.; BORRELLI, J. ;ANDERSON, D. A. Distribution patterns of home lawn sprinklers. Transactions of the ASAE, v. 23, n.2, p. 387-92, 1980.

$\mathrm{KOHL}, \mathrm{R}$. A. Drop size distribution from medium-size agricultural sprinklers. Transactions of the ASAE, v.17, n.4, p. 690-3, 1974.

LETEY, J.; DINAR, A.; WOODRING, C.; OSTER, J. D. An economic analysis of irrigation systems. Irrigation Science, v. 11, n.2, p. 37-43, 1990.

LOPEZ, J. Riego por aspersion. Centro de Treinamento em Irrigação, Petrolina, Pernambuco, SUDENE, convênio MINTER-IICA, julho, 1975. $33 p$.

MERRINGtON, A. C; RIChaRdson, E. G. The breakup of liquid jets. Proc. Phy. Soc., London, v. 59, n.2, p. 1-13, 1947.

OLITTA, A. F. L.. Os métodos de irrigação. São Paulo: Ed. Nobel, 1978. $267 p$.

PAIR, C. H.; HINZ, W. W.; REID, C.; FROST, K. R. Sprinkler irrigation. 3.ed. Washington: Sprinkler Irrigation Association, 1968. 444p.

PAZ, V. P. S. Perdas de água e uniformidade na irrigação por aspersão. Viçosa, 1990. 59p. Dissertação (Mestrado em Engenharia Agrícola)Universidade Federal Viçosa.

ROUSE, H.; HOWE, J. E.; METZLER, D. E. Experimental investigation of fire monitors and nozzles. American Society of Civil Engineering, v. 117, p.1147-88, 1952. 
SATTO, J. Avaliação do desempenho dos aspersores. São Carlos, 1978, 77p. Dissertação (Mestrado-Escola de Engenharia de São Carlos, Universidade de São Paulo).

SEGINER, 1. Wind variation and sprinkler water distribution. Journal of the Irrrigation and Drainage Division, v.95, n. IR2, p. 261-75. 1969.

SHULL, H; DYLLA, A. S. Wind effects on water application patterns from a large, single nozzle sprinkler. Transactions of the ASAE, v.19, n. 3, p. 501-504. 1976.

SMITH, M. Report on the expert consultation on procedures for revision of FAO guidelines for predictions of crop water requirements. Rome: FAO, 1991. 45p.

SOARES, A. A.; WILLARDSON, L. S.; KELLER, J. Surface-slope effects on sprinkler uniformity. Journal of Irrigation and Drainage Engineering, v.117, n. 6, p. 870-9, 1991.

SOLOMON, K. Variability of sprinkler coefficient od uniformity test results. Transactions of the ASAE, v.22, n. 5, p. 1070-80, 1086, 1979.

SOLOMON, K.; BEZDEK, J. C. Characterizing sprinkler distributions pattern with a clustering algorithm. Transactions of the ASAE, v. 23, n. 4, p. 899906, 1980.

WILCOX, J. C; SWAILES, G. E. Uniformity of water distribution by some undertree orchard sprinklers. Scientific Agriculture, v. 27, n 11, p. 565-83, 1947. 
WILLMOTT, C. J. Some comments on the evaluation of model performance. American Meteorological Society, Bulletin, v. 63, n. 11, p. 1309-13. nov, 1982.

WITHERS, B; WIPOND, S. Irrigação: projeto e prática. São Paulo, EPU, 1977. 339p. 


\section{APÊNDICE 1}

ILUSTRAÇÃO DAS SUPERFÍCIES DE RESPOSTA, OBTIDAS COM O USO DO PROGRAMA CATCH3D, VERSÃO 4.21. 


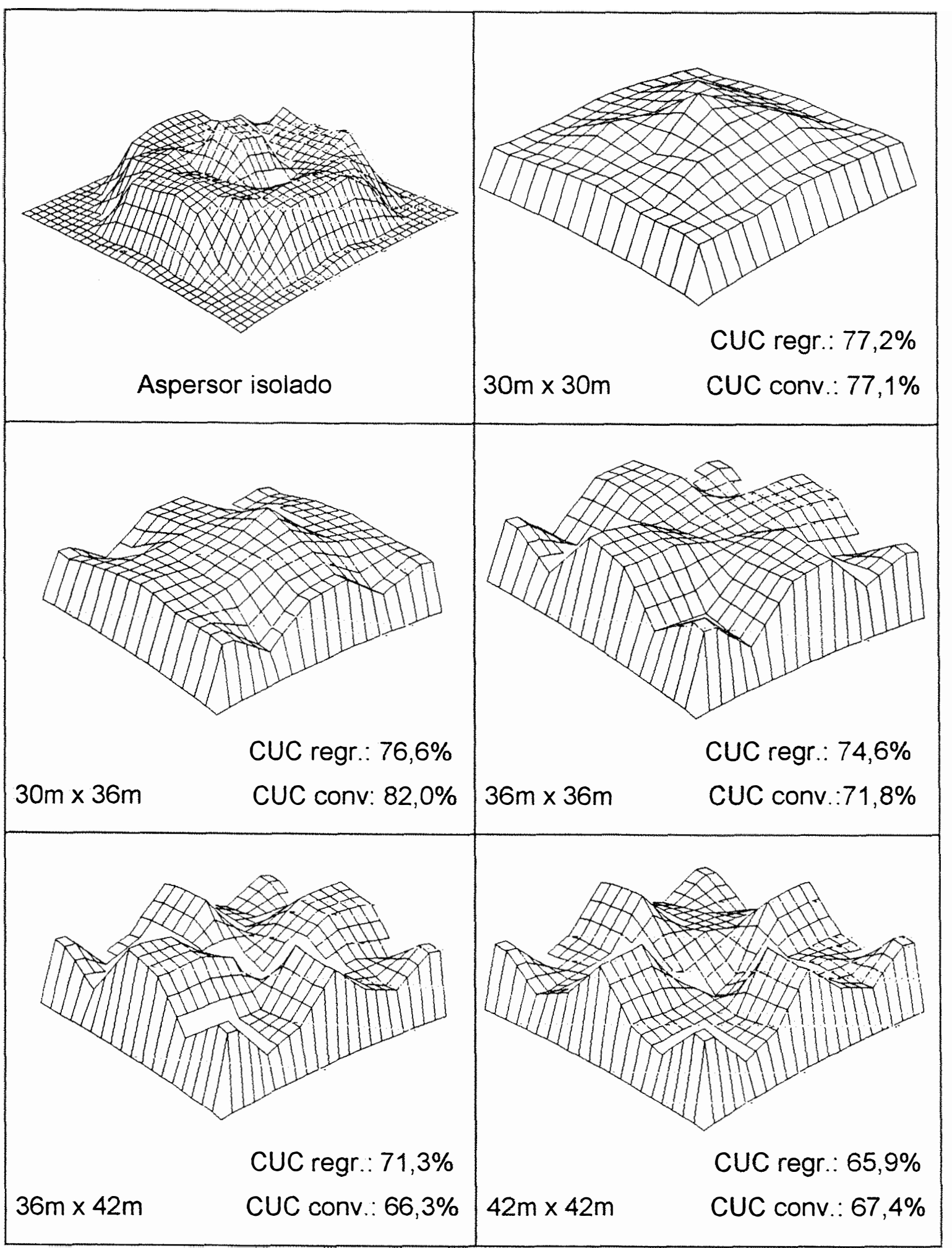

Figura 1.1: Superfícies de resposta da distribuição das lâminas de água do aspersor ZN e coeficientes de uniformidade de Christiansen (CUC), para ângulo de $18^{\circ}$ e pressão de $300 \mathrm{kPa}$. 


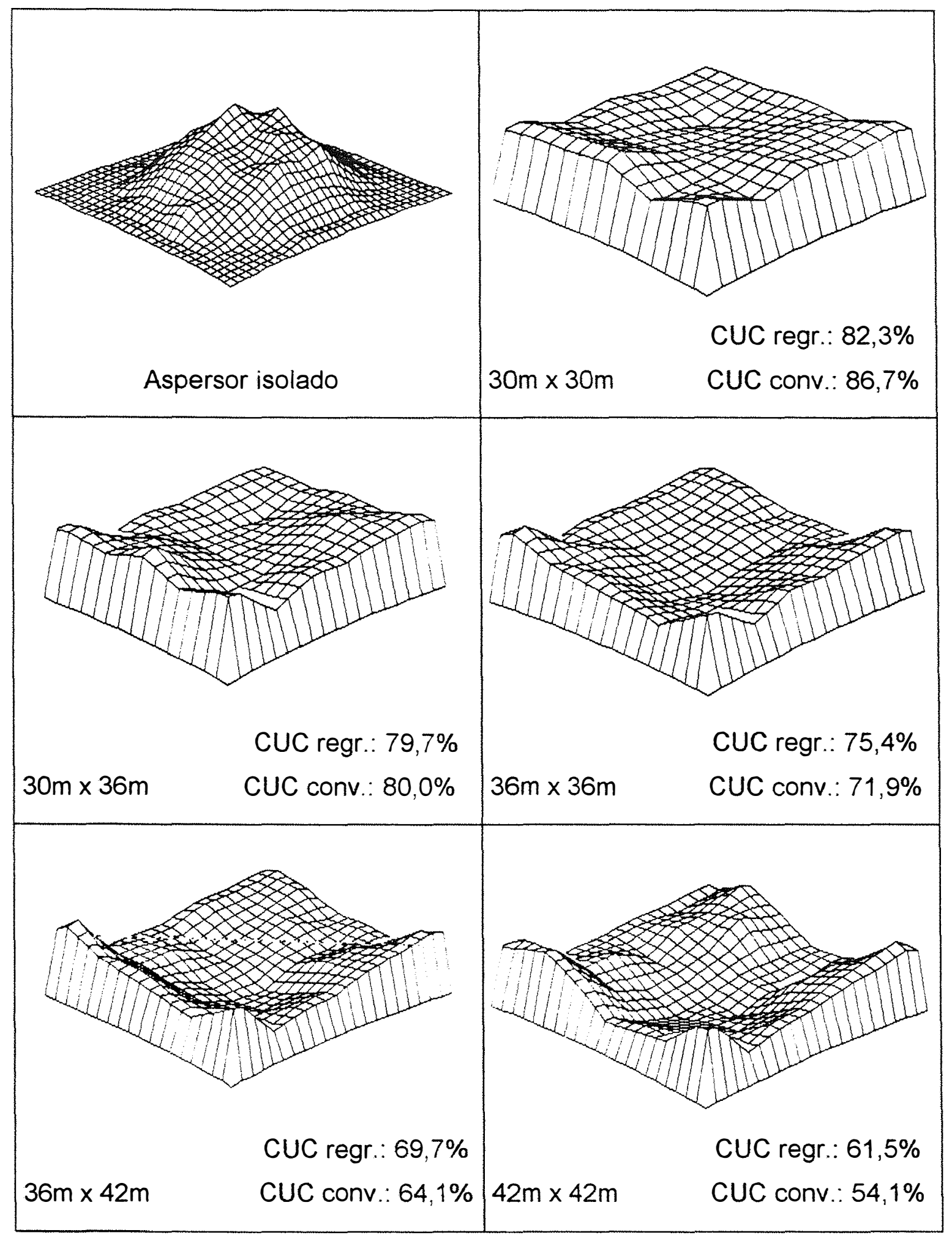

Figura 1.2: Superfícies de resposta da distribuição das lâminas de água do aspersor $\mathrm{ZN}$ e coeficientes de uniformidade de Christiansen (CUC), para ângulo de $24^{\circ}$ e pressão de $400 \mathrm{kPa}$. 


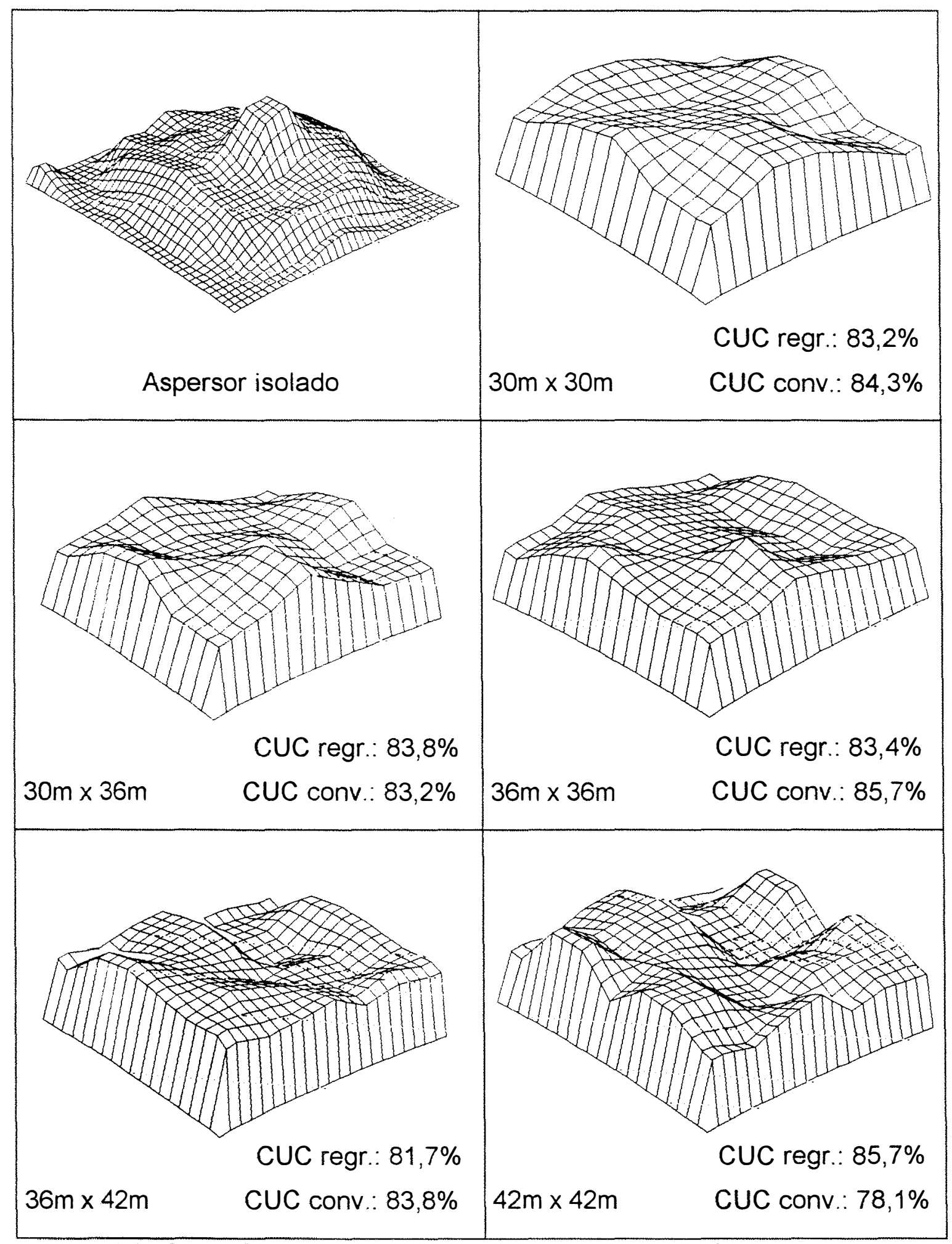

Figura 1.3: Superfícies de resposta da distribuição das lâminas de água do aspersor $\mathrm{ZN}$ e coeficientes de uniformidade de Christiansen (CUC), para ângulo de $24^{\circ}$ e pressão de $450 \mathrm{kPa}$. 


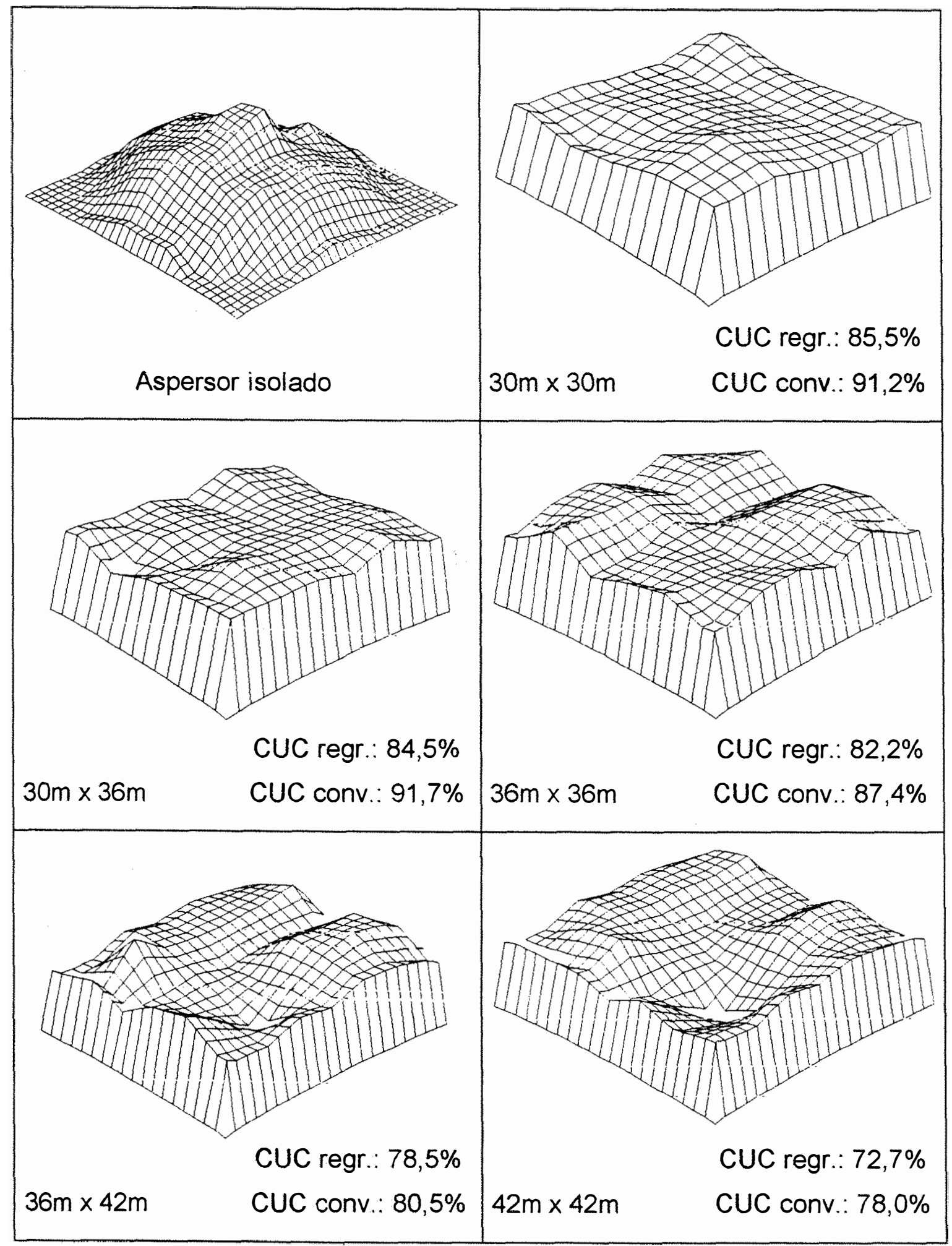

Figura 1.4: Superfícies de resposta da distribuição das lâminas de água do aspersor $\mathrm{ZN}$ e coeficientes de uniformidade de Christiansen (CUC), para ângulo de $27^{\circ}$ e pressão de $350 \mathrm{kPa}$. 